\title{
Impact of cloud parameterization on the numerical simulation of a super cyclone
}

\author{
M. S. Deshpande, S. Pattnaik, and P. S. Salvekar \\ Indian Institute of Tropical Meteorology, Pashan Road, NCL Post, Pune-411008, India \\ Correspondence to: M. S. Deshpande (medha_d@tropmet.res.in) \\ Received: 24 October 2011 - Revised: 12 February 2012 - Accepted: 4 April 2012 - Published: 7 May 2012
}

\begin{abstract}
This study examines the role of parameterization of convection and explicit moisture processes on the simulated track, intensity and inner core structure of Orissa super cyclone (1999) in Bay of Bengal (north Indian Ocean). Sensitivity experiments are carried out to examine the impact of cumulus parameterization schemes (CPS) using MM5 model (Version 3.7) in a two-way nested domain (D1 and D2) configuration at horizontal resolutions $(45-15 \mathrm{~km})$. Three different cumulus parameterization schemes, namely Grell (Gr), Betts-Miller (BM) and updated Kain Fritsch (KF2), are tested. It is noted that track and intensity both are very sensitive to CPS and comparatively, KF2 predicts them reasonably well. Particularly, the rapid intensification phase of the super cyclone is best simulated by KF2 compared to other CPS. To examine the effect of the cumulus parameterization scheme at high resolution $(5 \mathrm{~km})$, the three-domain configuration (45-15-5 km resolution) is utilized. Based on initial results, KF2 scheme is used for both the domains (D1 and D2). Two experiments are conducted: one in which KF2 is used as CPS and another in which no CPS is used in the third domain. The intensity is well predicted when no CPS is used in the innermost domain. The sensitivity experiments are also carried out to examine the impact from microphysics parameterization schemes (MPS). Four cloud microphysics parameterization schemes, namely mixed phase (MP), Goddard microphysics with Graupel (GG), Reisner Graupel (RG) and Schultz (Sc), are tested in these experiments. It is noted that the tropical cyclone tracks and intensity variation have considerable sensitivity to the varying cloud microphysical parameterization schemes. The MPS of MP and Sc could very well capture the rapid intensification phase. The final intensity is well predicted by MP, which is overestimated by Sc. The MPS of GG and RG underestimates the intensity.
\end{abstract}

Keywords. Meteorology and atmospheric dynamics (Tropical meteorology)

\section{Introduction}

Clouds have a significant impact on weather. They produce heating and cooling, transport mass, heat and momentum vertically and horizontally, and disturb their surroundings by generating precipitation, intense winds, and turbulence. When the clouds and their constituent particles and/or their effects are unresolvable by a numerical model, parameterizations become necessary. Cloud processes can be treated implicitly through convective parameterization schemes or explicitly through cloud microphysics schemes in a numerical model. The implicit scheme is used to remove the convective instability and the explicit scheme allows treating the cloud precipitation processes on the convectively stable and nearly neutral layer (Zhang et al., 1988; Molinari and Dudek, 1992). These two precipitation producing schemes (known as cloud or moist parameterization schemes) control the spatial and temporal distribution of precipitation and consequently can yield distinct vertical profiles of heating and moistening in the atmosphere. In weather forecasting models, at horizontal grid spacing greater than $10 \mathrm{~km}$, convective and cloud microphysics parameterization are required to compensate for unresolvable convective activity (Stensrud, 2007). Both parameterizations contribute to represent the convective activity without double-counting its thermodynamic impacts (Zhang et al., 1988).

The convective activity modifies the large-scale temperature and moisture fields through detrainment and storminduced subsidence in the surrounding environment. Detrainment creates large-scale cooling and moistening, while 
the local subsidence creates large-scale warming and drying. Convective parameterization schemes attempt to account for these large-scale effects. The importance of cumulus convection within tropical cyclones has been recognized for a long time and one of the reasons for developing cumulus parameterization scheme (CPS) was to represent the effect of subgrid scale cumulus clouds in simulating tropical cyclones using grid-scale prognostic variables (Smith, 2000). A cloud is composed of more than billions of condensed water particles: free-floating cloud droplets, rain drops, ice crystals, snowflakes, moderate density graupel particles and higher density ice like hail. Numerical models cannot track every particle, so the physics of condensation creation, growth, destruction and motion has to be parameterized. Cloud microphysics refers to how these processes are handled in a model. It is the physical processes that describe the formation (activation), growth, decay, and fallout of cloud and precipitation particles. The latent heat release in tropical cyclones indirectly provides heating through forced indirect circulation in the eye. A warm-core structure is essential for the development and maintenance of the circulation of the storm. The latent heat release in clouds depends on the rates of microphysical processes. A major portion of the latent heat release is contributed by the cloud microphysical processes.

Several studies examined the sensitivity of tropical cyclone forecast to the formulation of cumulus and cloud microphysics parameterization schemes. On the basis of analysis-forecast experiment with ECMWF (European Centre for Medium-Range Weather Forecasts) operational global model, Puri and Miller (1990) reported more intense tropical cyclones with the Betts and Miller (1986) convective adjustment scheme than with the Kuo scheme (Kuo and Anthes, 1984). Baik et al. (1991) compared Betts (1986) and Kuo schemes (Kuo, 1974; Anthes, 1977), through numerical simulations of tropical cyclone with an axisymmetric model. They showed that the storms begin to intensify when gridscale heating extended through a deep layer, and that the later development of the storm with the Betts scheme resulted from a delayed onset of grid-scale heating. They also found that the storm evolution with both cumulus parameterization schemes was sensitive to inclusion of the cooling effect of raindrop evaporation. Tsutsui et al. (1998) conducted forecast experiments for tropical cyclones with a limited area model. They investigated the impact of two cumulus parameterization schemes, namely a relaxed Arakawa-Schubert scheme proposed by Moorthi and Suarez (1992) and Kuo (1974) scheme, on tropical cyclone prediction. Their results suggest that the former appeared more suitable than the later for the intensity prediction of developing tropical cyclones, whereas the use of the later produced better scores in mean displacement errors. Murata and Ueno (2000) investigated the effects of two cumulus parameterization schemes, namely Arakawa-Schubert (Arakawa and Schubert, 1974; Kuma et al., 1993) and a moist convective adjustment scheme (Gadd and Keers, 1970) on the intensity simulation of ty- phoon Flo (1990). The intensity simulation was more realistic and the precipitation averaged within the core region of the storm was significantly greater in the ArakawaSchubert scheme. The vertical instability was excessively eliminated when the moist convection adjustment scheme was used, which suppressed the band formation. Davis and Bosart (2002) studied the effects of cumulus parameterization on tropical storm track and intensity. They found that the Betts-Miller-Janjic (Betts and Miller, 1993) and Grell (1993) schemes produced a more westward track than Kain-Fritsch (Kain and Fritsch, 1993). The Kain-Fritsch scheme tended to intensify the storm too rapidly, but produced the best track compared with observations.

In general, for grid sizes smaller than $5 \mathrm{~km}$, only the parameterization of microphysical processes is used, because cumulus clouds can be resolved (Weisman et al., 1997). However, a study by Kotroni and Lagouvardos (2004) suggests that inclusion of cumulus parameterization in mesoscale model at $2 \mathrm{~km}$ resolution improves the precipitation forecast. It is known that a tropical cyclone comprises both mesoscale and deep convective organization of clouds. The models with horizontal resolution of $10 \mathrm{~km}$ are able to somewhat resolve the mesoscale component, but in order to get information from deep convection, one may still need parameterization. Recently, Mukhopadhyay et al. (2011) have studied the influence of moist processes on track and intensity forecast of cyclones Gonu and Sidr over the north Indian Ocean using WRF. They found that hybrid moist convection treatment (which included CPS and MPS both) at $10 \mathrm{~km}$ horizontal resolution is found to produce a better simulation as compared to only explicit microphysics experiments at $3.3 \mathrm{~km}$. The main reason is the heating within the inner core of the cyclone, which is influenced dominantly by production of graupel hydrometeors in the inner core region. The latent heat released in the formation of graupel mixing ratio is responsible for net middle level heating rate in the cyclone core. Higher net heating in the middle level enhances the divergence in the upper level and convergence in the lower level, which in turn helps in the intensification of the system.

Cloud microphysical processes have been shown to be critical to the realistic simulation of clouds and precipitation by numerical models (McCumber et al., 1991; Meyers et al., 1992; Brown and Swann, 1997). In early days only warmrain cloud microphysics was considered (Yamasaki, 1977; Rosenthal, 1978; Jones, 1980) for tropical cyclone simulations. Willoughby et al. (1984) and Lord et al. (1984) found that the inclusion of ice processes in an axisymmetric, nonhydrostatic model has resulted in a stronger storm. They also showed that more realistic downdrafts and convective rings were produced with the mixed ice phase cloud microphysics scheme. Lord and Lord (1988) demonstrated that the latent heat release through the graupel conversion process actually contributes to mesoscale organization of moist convection. Wang (2002) examined the sensitivity of tropical cyclone development to cloud microphysics schemes and 
reported that the intensification rate and final intensity are not sensible to cloud microphysics, but only produce differences in the cloud structure. Zhu and Zhang (2006) showed that suppressing the microphysical processes, such as evaporation and melting, has produced a rapid intensification and lower central pressure. Fovell and Su (2007) showed that using the modification of microphysical and cumulus parameterization significantly influenced the track and land fall of Hurricane Rita. Pattnaik and Krishnamurti (2007a, b) investigated the impact of cloud microphysical processes on hurricane intensity using $4 \mathrm{~km}$ resolution simulations. They found that inter-conversion processes, such as melting and evaporation among the hydrometeors and associated feedback mechanism, significantly modulate the intensity of the Hurricane Charlie. Their result indicates that whenever the sources of heat sinks are reduced, latent heating produces more instability, an increased buoyancy gradient, and higher tropical cyclone intensity. Recently, Pattnaik et al. (2011) examined the direct and indirect impacts on the intensity forecast of the tropical cyclone due to the limited modifications in the ice and snow parameters of the model explicit scheme. They also noted that the variations in distribution pattern of hydrometeors in the eyewall region of the storm strongly impact its diabatic heating and vertical velocity structure and hence modulate the storm intensity.

Attempts have also been made to simulate the intensity and movement of cyclones over the north Indian Ocean basins. Srinivas et al. (2007) studied the sensitivity of the PBL and convective parameterization schemes to the numerical simulation of Andhra severe cyclone (2003) in the Bay of Bengal. Mandal et al. (2004) studied the impact of various physical parameterization schemes on the prediction of two tropical cyclones formed during November 1995 over the Bay of Bengal using MM5. Deshpande et al. (2010) studied the sensitivity of various physical parameterization schemes on the numerical simulation of Super Cyclone Gonu and reported that the forecast track and intensity of the cyclone are most sensitive to CPS, compared to other physical parameterization schemes (e.g. PBL and MPS). Other parameterizations like air-sea fluxes, boundary layer, radiation, turbulence as well as initial and boundary conditions can also have an impact on the storm track and intensity.

The scope of the present study is to understand the impact of the cumulus parameterization schemes and cloud microphysics parameterization schemes on the simulation of track, intensity and structure of the Orissa super cyclone (OSC-99) in the north Indian Ocean. Numerical studies of OSC-99 using MM5 are available in the literature (Mohanty et al., 2004; Trivedi et al., 2002, 2006; Rao and Prasad, 2006, 2007; Mandal and Mohanty, 2006). All these studies have mainly focused on comparisons of the track and intensity of OSC-99 with various resolutions and parameterization schemes. Detailed evaluation regarding the combination of specific parameterization schemes is absent. Also, all these studies failed to simulate the final intensity and

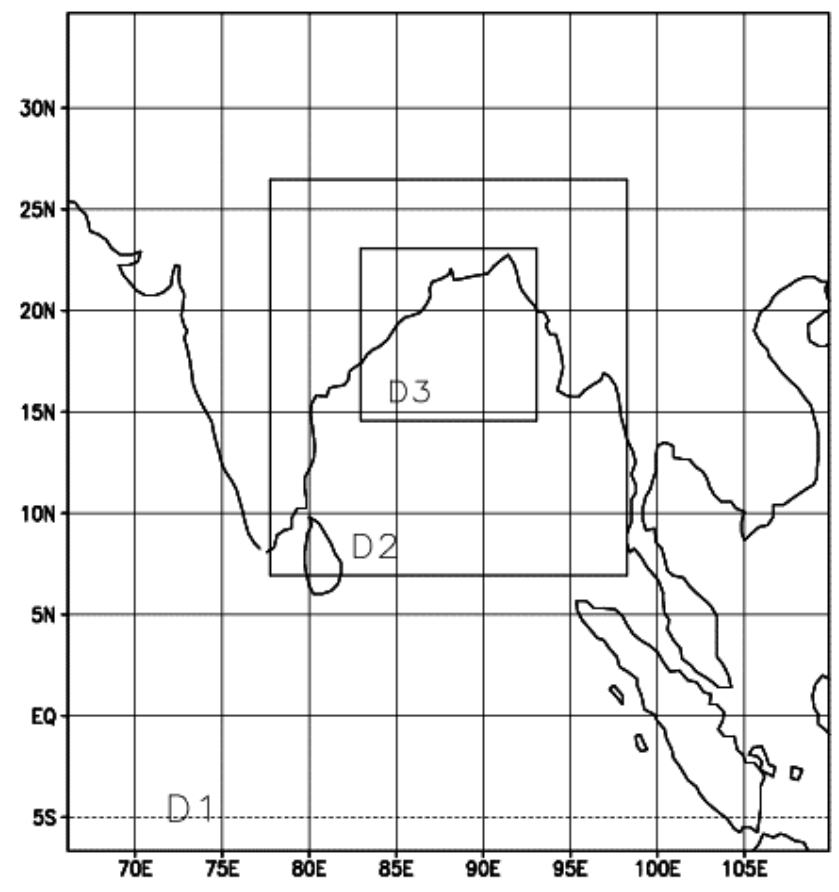

Fig. 1. Model domains configuration for numerical simulation experiments of Orissa super cyclone 1999.

fast intensification of OSC-99. Most likely, the reason for this failure is due to the implementation of coarser horizontal resolution in the model simulations to resolve the convective scale processes. In this study we have investigated the impact of cumulus parameterization schemes and cloud microphysical parameterization schemes on the simulation of forecast track, intensification and inner core structure of the Orissa super cyclone using Pennsylvania State University-National Center for Atmospheric Research (PSUNCAR) non-hydrostatic Mesoscale Model (MM5; Dudhia, 1993; Grell et al., 1995). To understand the impact of explicit parameterization schemes, a triply-nested configuration with the innermost domain having the highest resolution of $5 \mathrm{~km}$ is used. In the next section details about experiment design, numerical model and data used, followed by the brief description of the Orissa super cyclone obtained from India Meteorology Department report (IMD, 2000) are given. Results and discussions of experiments of cumulus parameterization schemes and cloud microphysics parameterization schemes are illustrated in Sects. 3 and 4, respectively. Section 5 gives the concluding comments.

\section{Model configuration and synoptic description of Orissa super cyclone}

The Penn State University-NCAR non-hydrostatic mesoscale model (MM5) version 3.7 is used in this study (Grell, 1995). Experiments of cumulus parameterization scheme are 
conducted with two-way interactive nested domains at $45 \mathrm{~km}$ (domain D1 $-110 \times 110$ grid points) and $15 \mathrm{~km}$ (domain D2 $-154 \times 154$ grid points) horizontal resolution, as shown in Fig. 1. Overview of MM5 model configuration used in this study is given in Table 1 . There are 23 vertical unequal sigma $(\sigma)$ levels with higher resolution in the planetary boundary layer (PBL). The top of the model is set to $100 \mathrm{hPa}$. The simulation is initialized with ECMWF reanalysis (ERA-40) data (Uppala et al., 2005) at 12:00 UTC, 25 October 1999, when the system was in the depression stage with maximum sustained wind of 25 knots. The initial conditions for the nested domains are obtained by interpolating fields from their respective mother domains. Lateral boundary condition is provided to D1 at every 12-h interval from the ERA-40 data. The coarser meshes provide the time-dependent lateral boundary conditions to the finer meshes while the finer-mesh solutions are fed back to coarser mesh at every time step, thereby achieving the two-way interaction of the meshes. During first $24 \mathrm{~h}$ only, outermost domain (D1) is active. Domain D2 is activated at 12:00 UTC, 26 October 1999. No special observations were available near the initial time and bogus vortex is not inserted because of the weak (tropical depression stage) and asymmetric structure of the observed storm at the initial time. The model was forced with sea surface temperature (SST) derived from skin temperature in an ERA-40 reanalysis data set. It should be mentioned here that along the track of the storm, the ERA-40 skin temperature and observed SST are mostly over $29^{\circ} \mathrm{C}$. According to DeMaria and Kaplan (1994), the SST and its gradient have the greatest influence on intensity of the storm when it varies within the range 26$29^{\circ} \mathrm{C}$. With SST value greater than $29^{\circ} \mathrm{C}$, the SST gradient has relatively less impact on the intensification of cyclonic storms.

Initially, the sensitivity to cumulus parameterization schemes is carried out. Other physical parameterizations include the Mellor Yamada (MY, Mellor and Yamada, 1982) planetary boundary layer scheme, the mixed phase (MP, Reisner et al., 1998) microphysics scheme, and the NCAR community climate model (CCM2) (Briegleb, 1992; Kiehl et al., 1994) radiation parameterization scheme. The three cumulus parameterization schemes considered here are namely Grell (Grell, 1993), Betts-Miller (Betts and Miller, 1986) and updated Kain-Fritsch (Kain and Fritsch, 1993; Kain, 2004) schemes.

The Grell (Gr) scheme is the convective mass flux scheme. The parameterization is based on the rate of destabilization of only one cloud type with subgrid-scale updraft and downdraft, and grid-scale compensating subsidence. There is mixing between clouds and environment only at the top and the bottom. Betts-Miller (BM) is a moist convective adjustment scheme, where the thermodynamic profile is adjusted toward the observed reference profile. The scheme essentially removes the conditional instability in each grid column by adjusting the vertical profile of temperature and specific humidity toward the reference profile, which is derived based on the observations of Betts (1986) and Betts and Miller (1986). The scheme gets triggered if a parcel, when lifted moist adiabatically from the lower troposphere to a level above the cloud base, becomes warmer than the environment. However, the scheme does not include the moist processes below the cloud base and mostly in the lower boundary layer. Activation of BM scheme at a particular grid point is mainly determined by thermodynamics. Vertical motion by moistening the low and mid levels can enhance activation of the scheme, but there is no direct impact. The Kain-Fritsch scheme is designed to simulate a vertical rearrangement of mass that eliminates convective available potential energy (CAPE) within a specified timescale (approximately $30 \mathrm{~min}$ ) and its trigger is based on the grid-resolved vertical motion (Kain and Fritsch, 1993). This vertical motion $(w)$ is used to calculate a temperature perturbation scaled as $w^{1 / 3}$ and this temperature perturbation is used to determine whether a parcel can overcome its convective inhibition. The updated Kain Fritsch scheme (KF2) allows shallow convection, includes a minimum entrainment rate to suppress widespread convection in marginally unstable, relatively dry environments, and has changes in the downdraft formulation. Downdrafts in KF2 are formed from air in the layer at $150-200 \mathrm{hPa}$ above cloud base, and detrain over a fairly deep layer below cloud base. Downdraft mass flux is estimated as a function of the relative humidity and stability just above cloud base, but is no longer related to vertical wind shear (Kain, 2004). The surface convergence with the induced vertical motion has a much bigger impact on the KF convective parameterization than on the BM convective parameterization.

The sensitivity to CPS is carried out with a two-domain configuration and then the experiment with and without CPS is carried out utilizing three-domain configuration. Third domain with $5 \mathrm{~km}$ resolution (domain D3 $-226 \times 202$ ) is activated at 12:00 UTC of 27 October 1999. The sensitivity to the microphysics parameterization schemes (MPS) is carried out with three-domain configuration. Four MPSs, namely mixed phase (Reisner et al., 1998) scheme, Goddard scheme with graupel (Tao and Simpson, 1993; modified by Braun and Tao, 2000), Reisner's Scheme with graupel (Reisner et al., 1998; modified by Thompson et al., 2004) and Schultz scheme (Sc, Schultz, 1995), are considered. These four microphysics schemes considered here predict frozen hydrometeors. Reisner's mixed-phase (MP) scheme includes cloud and rain water, ice and snow, but does not consider riming processes or graupel formation. Goddard microphysics (GG) scheme is a bulk, single-moment microphysical scheme, in which the prognostic equations include water vapour, cloud water, rain water, cloud ice, snow, and graupel. Reisner's mixed-phase with graupel (RG) scheme is a bulk doublemoment scheme in which the prognostic equations include water vapour, cloud water, rain water, cloud ice, snow, and graupel, plus number concentration of cloud ice. Schultz mixed-phase $(\mathrm{Sc})$ scheme includes cloud water, cloud ice, 


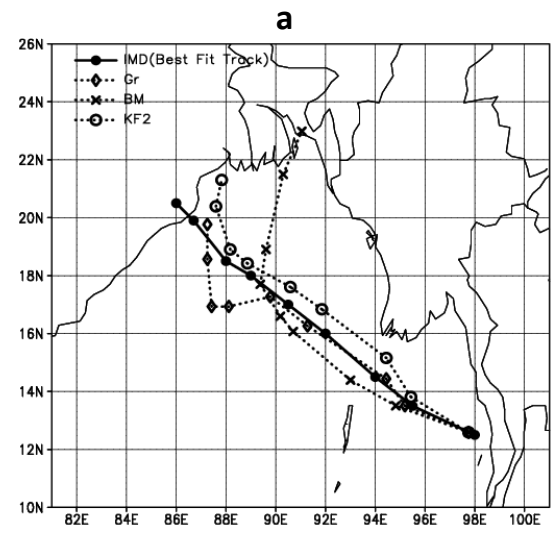

b

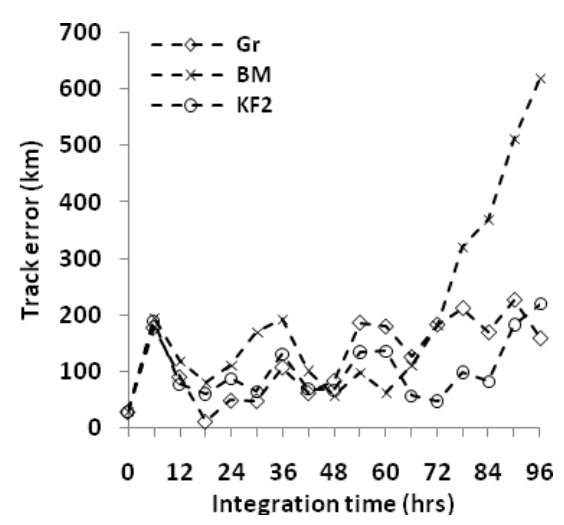

c

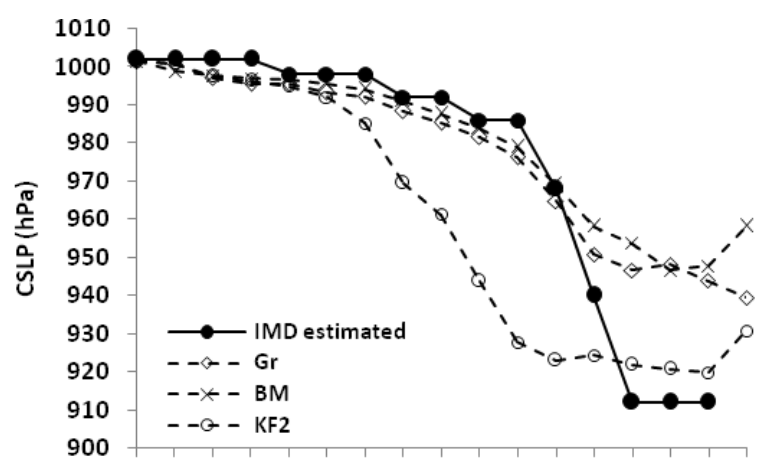

06121824303642485460667278849096 Integration time (hrs)

d

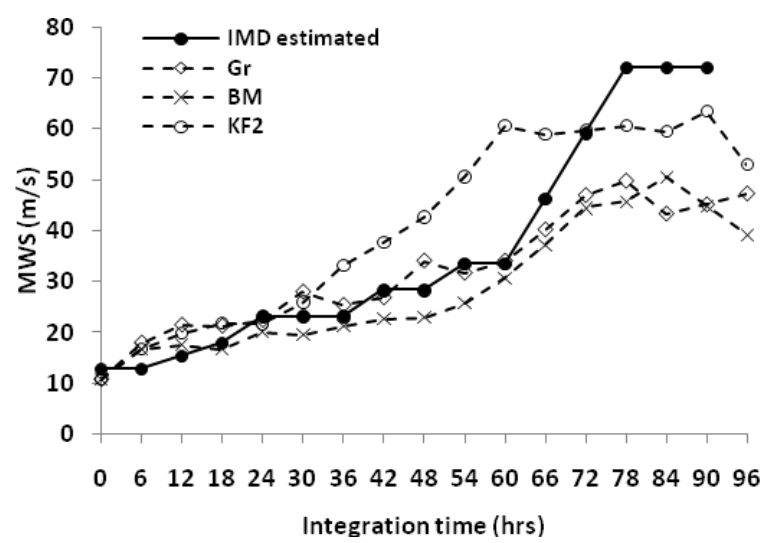

Fig. 2. (a) model simulated tracks and time series plots of (b) track error, (c) central sea level pressure (CSLP) in hPa and (d) maximum wind speed (MWS) in $\mathrm{m} \mathrm{s}^{-1}$ for the experiments with different CPS, namely Gr, BM and KF2 along with IMD data. The model integration is started on 12:00 UTC, 25 October 1999.

rain, snow, and precipitating ice such as graupel, sleet, and hail.

\subsection{Synoptic conditions}

In the Andaman Sea on 25 October, a depression formed, which intensified into a deep depression by 12:00 UTC of the same day and located near $12.5^{\circ} \mathrm{N} / 98.0^{\circ} \mathrm{E}$. Moving in the west of northwest direction, it intensified into a cyclonic storm with central sea level pressure (CSLP) of $1002 \mathrm{hPa}$ and maximum sustained surface wind speed (MSSWS) of $18 \mathrm{~m} \mathrm{~s}^{-1}$ centered near $13.5^{\circ} \mathrm{N} / 95.0^{\circ} \mathrm{E}$ at 03:00 UTC 26 October 1999. The next day by 03:00 UTC, 27 October 1999, it intensified into severe cyclonic storm with CSLP of $992 \mathrm{hPa}$ and MSSWS of $28 \mathrm{~m} \mathrm{~s}^{-1}$. At this stage it came under the influence of the upper level $(200 \mathrm{hPa})$ ridge, providing the outflow that helped further intensification of the storm and it classified into a very severe cyclonic storm (CSLP of $986 \mathrm{hPa}$ and MSSWS of $33 \mathrm{~m} \mathrm{~s}^{-1}$ ) by 15:00 UTC of the same day. By 00:00 UTC, 28 October 1999, the upper level outflow came nearly over the centre of the storm, which further intensified it into Super Cyclonic Storm (MSSWS exceeding $72 \mathrm{~m} \mathrm{~s}^{-1}$ ) by 15:00 UTC of the same day near $19.0^{\circ} \mathrm{N} / 87.5^{\circ} \mathrm{E}$. The estimated central pressure fell by $56 \mathrm{hPa}$ between 06:00 and 18:00 UTC, 28 October, indicating the rapid intensification phase of the storm's life cycle. The lowest estimated central pressure for the storm was $912 \mathrm{hPa}$. The storm crossed Orissa coast close to south of Paradip $\left(20.5^{\circ} \mathrm{N} / 86.5^{\circ} \mathrm{E}\right)$ around 05:30 UTC, 29 October and weakened into a very severe cyclonic storm. It remained stationary over Orissa and further weakened into a cyclonic storm till 03:00 UTC, 30 October 1999. Further moving in northeast direction it rapidly weakened into a depression with its centre near $20.5^{\circ} \mathrm{N} / 87.0^{\circ} \mathrm{E}$ at 03:00 UTC, 31 October 1999 and then by evening, it weakened into a well-marked, low-pressure area over northwest Bay of Bengal and adjoining parts of north Orissa-west Bengal coast (IMD, 2000). The observed (IMD) track and intensity are plotted in Fig. 2a, c-d which is used to validate the model simulations. This super cyclone lashed most parts of the Orissa coast and had tidal waves of height $12-14 \mathrm{~m}$, which inundated low-lying areas along the Orissa coast. As per the information received through 
(a) Gr $48 \mathrm{hrs}$

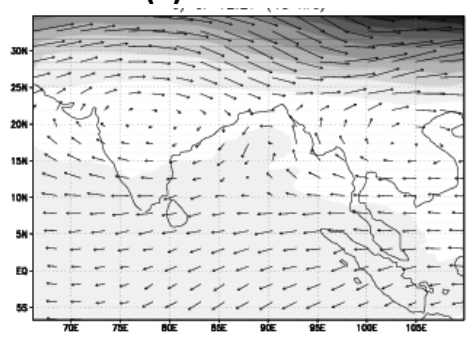

(b) Gr 60

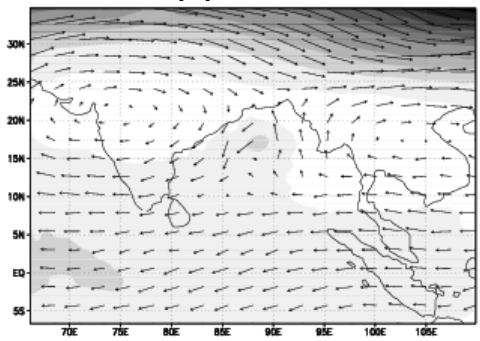

(c) Gr 72 hrs

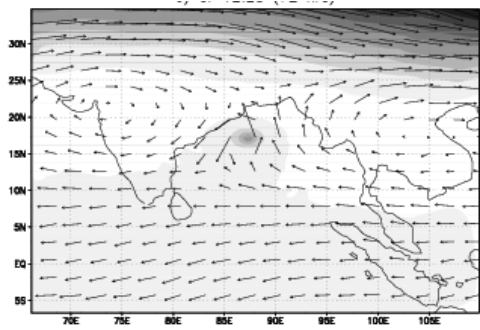

(d) Gr $84 \mathrm{hrs}$

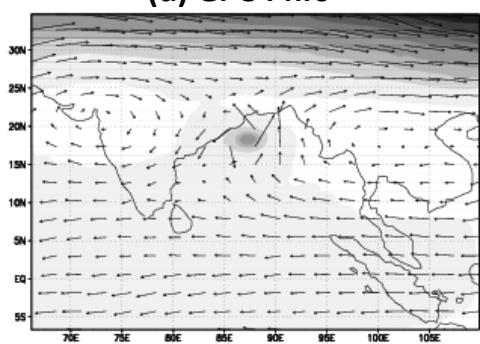

(e) BM 48 hrs

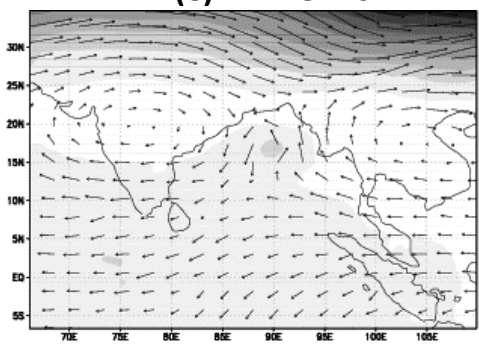

(f) BM $60 \mathrm{hrs}$

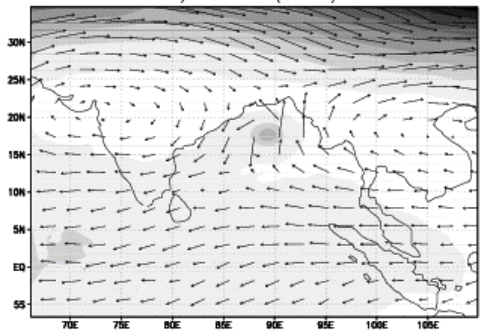

(g) BM 72 hrs

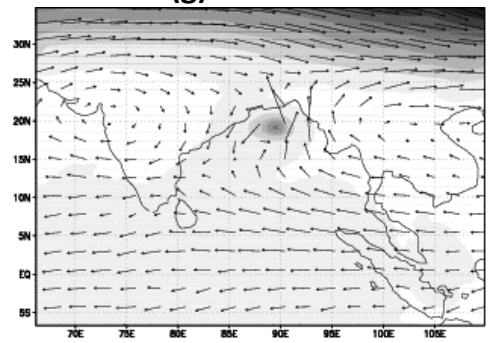

(h) BM 84 hrs

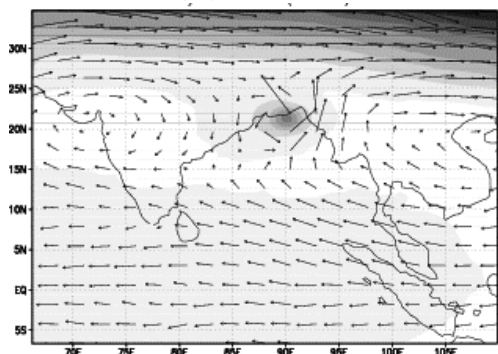

(i) KF2 $48 \mathrm{hrs}$

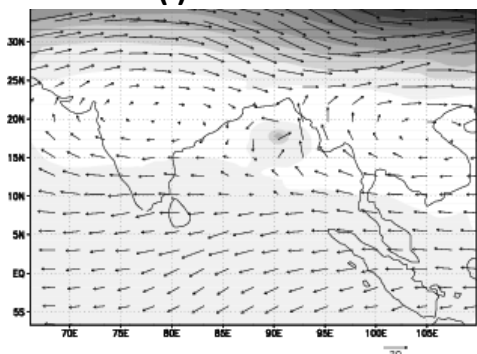

(j) KF2 $60 \mathrm{hrs}$

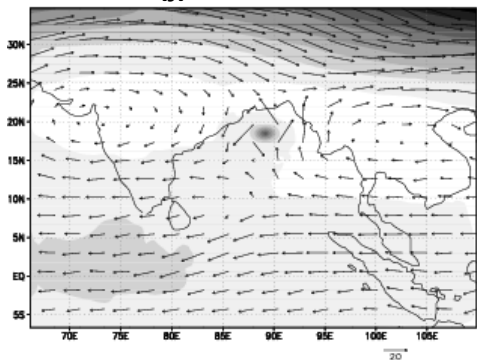

(k) KF2 72 hrs

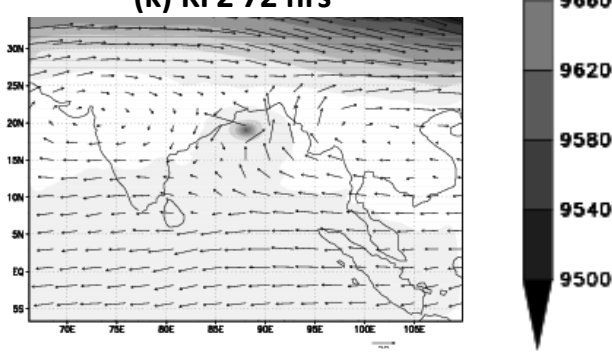

(I) KF2 $84 \mathrm{hrs}$

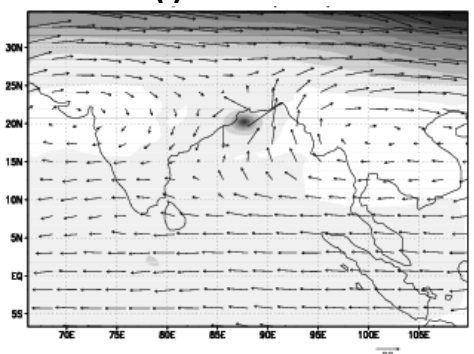

Fig. 3. Layer-averaged $(400 \mathrm{hPa}-200 \mathrm{hPa})$ geopotential height in meters (shaded) and wind direction and magnitude in $\mathrm{m} \mathrm{s}^{-1}$ (vectors), simulated by CPS of Gr (a)-(d), BM (e)-(h) and KF2 (i)-(l) each at 48, 60, 72 and $84 \mathrm{~h}$ of integration.

media, 15000 people lost their lives and the storm caused extensive damage to property, crops and plantations, communication and transportation networks, estimated to be worth INR 10000 crores (approximately equivalent to 1892 million US \$) (The Economic Times, 1 March 2000).

\section{Sensitivity to cumulus parameterization schemes (CPS)}

In this set, experiments are performed with the variation of the parameterization scheme for convection as Grell (Gr),
Betts-Miller (BM) and Kain-Fritsch 2 (KF2), in combination with Mellor Yamada (MY) scheme for PBL processes and mixed phase (MP) scheme for explicit moisture processes. The plots of track, track error and intensity variation with time for sensitivity to CPS are shown in Fig. 2a-d. The simulated tracks for all the schemes are northwestward, close to the observed track up to $48 \mathrm{~h}$ of integration. Thereafter, $\mathrm{Gr}$ track is straight westward up to $78 \mathrm{~h}$ and then towards north. The track error increases sharply after $60 \mathrm{~h}$ of integration for BM due to northward bias in the simulated track. The track with KF2 is northwestward up to $84 \mathrm{~h}$, very close to 
the observed track. Thereafter, there is slight northward bias. The average track error is $124 \mathrm{~km}$ for $\mathrm{Gr}, 196 \mathrm{~km}$ for BM and $102 \mathrm{~km}$ for KF2. Different schemes have different methods of parametrising the potential vorticity. The changes in potential vorticity at the tropopause can cause changes in the wind field, which results in different tracks (Davis and Bosart, 2002).

The intensity variation is less sensitive for all three schemes up to $30 \mathrm{~h}$ of integration. Then onwards, KF2 overestimates the intensity up to $72 \mathrm{~h}$ of integration and thereafter slightly underestimates the intensity. The KF2 scheme is able to simulate the rate of intensification with sufficient accuracy even though the intensification is $12 \mathrm{~h}$ prior to that of observations. The intensity variation is similar for $\mathrm{Gr}$ and BM. Both give intensity comparable to the IMD estimated values up to $66 \mathrm{~h}$ of integration. Then onwards, both the schemes underestimated the intensity. The minimum CSLPs are $939 \mathrm{hPa}$ at 12:00 UTC, $947 \mathrm{hPa}$ at 00:00 UTC and $920 \mathrm{hPa}$ at 06:00 UTC of 29 October 1999 with $\mathrm{Gr}$, BM and KF2, respectively. The maximum wind speed (MWS) values are $50 \mathrm{~m} \mathrm{~s}^{-1}$ at 18:00 UTC of 28 October $1999,51 \mathrm{~m} \mathrm{~s}^{-1}$ at 00:00 UTC and $63 \mathrm{~m} \mathrm{~s}^{-1}$ at 06:00 UTC of 29 October 1999 for Gr, BM and KF2 respectively. Only KF2 could simulate the super cyclone (MWS $>62 \mathrm{~m} \mathrm{~s}^{-1}$ ) and the fast intensification.

Tropical cyclone motion is the result of a complex interaction between a number of internal and external influences. Environmental steering is typically the most prominent external influence on a tropical cyclone, accounting for as much as 70 to 90 percent of the motion (Neumann, 1992). The dominant influence on the movement is the large-scale environmental steering, which can be analysed from geopotential height, averaged over the layer of $400 \mathrm{hPa}-200 \mathrm{hPa}$. Figure 3 represents layer-averaged $(400 \mathrm{hPa}-200 \mathrm{hPa})$ geopotential height in meters (shaded) and wind direction (vectors), for Gr (a-d), BM (e-h) and KF2 (i-l), each at 48, 60, 72 and $84 \mathrm{~h}$ of integration. The changes in cumulus parameterization schemes play a dominant role in the characteristic evolution and maintenance of vortex size, radius of maximum winds and the intensity of the storm. Zhu and Zhang (2006) reported that the compact and weak storms are most influenced by large-scale deep-layer-averaged environmental flow (i.e. steering currents) compared to that of large and intense storms. In the case of OSC-99, there was an anticyclone over India, which tends to oppose the cyclone's northwestward motion and the cyclone was likely to move towards West Bengal. But the system intensified into a super cyclonic storm, and dominated over the anticyclone present over land and continued to move in the northwestward direction. The intensity of the BM simulated storm is weak, so the anticyclone over India opposes the northwestward movement and the cyclone travelled towards a north direction. Among these three CPS schemes, only KF2 could simulate the intense cyclone and thus could simulate the northwestward track. Along with the anticyclone over India, the westerly flow to the north of the system steered all the tracks in the north to northeastward direction after $78 \mathrm{~h}$ of integration (i.e. at 18:00 UTC of 28 October 1999). Since Gr and BM simulated storms are weaker, they hence tend to be more vulnerable to the influence of large-scale flow (Fig. 3g-h, k-1).

Primary factors that control tropical cyclone intensity include cloud dynamics and microphysics (Pattnaik et al., 2011), underlying surface (Tuleya, 1994; Bender and Ginis, 2000), and interaction with environmental flow (Wu and Cheng, 1999). In addition to these factors, vertical shear of the environmental flow is considered an important factor that can limit both the intensification and intensity of a TC (Wu and Cheng, 1999; Emanuel, 2004; Wang and Wu, 2004). Tropical cyclones are influenced by environmental, vertical wind shear at all stages of their life cycle (Gray, 1968; McBride and Zehr, 1981; Tuleya and Kurihara, 1981; Merrill, 1988). Wind shear causes asymmetry in eyewall convection, the upshear (downshear) side intensifies (weakens). Wind shear affects tropical cyclones by removing the heat and moisture they need from the area near their centre. Large vertical wind shears do not allow for area concentration of the tropospheric distributed cumulonimbus condensation. Large shears produce a large ventilation of heat away from the developing disturbance. Frank and Ritchie (2001) performed a series of numerical simulation experiments of tropical cyclones to examine the effects of vertical wind shear on the structure and intensity of hurricanes. They found that when relatively weak $\left(5 \mathrm{~m} \mathrm{~s}^{-1}\right)$ shear is added to the mean flow, the simulated storms rapidly developed stronger. On the contrary, strong shear $\left(10-15 \mathrm{~m} \mathrm{~s}^{-1}\right)$ dissipates the warm air in the upper layers, leading to overall weakening of the storm from the top to downward.

The distribution of latent heat released depends upon the cumulus parameterization schemes. The condensation heat released by the cumulus cloud to the upper troposphere is advected in a different direction relative to the released heat at lower levels. In an environment with strong shear, concentration of heat through the entire troposphere becomes more difficult, which inhibits the storm development (Gray, 1968). The cumulus parameterization scheme indirectly influences the wind shear. As we know, CPS schemes are largely controlled by large-scale environment; in addition, it also alters the large-scale environment through feedback mechanism. Distribution of heat and momentum within the clouds of tropical cyclone is mainly determined by the difference of temperature between cloud and environment, and convergence of moisture produced by large-scale environmental flow. Tropical storm development is possible due to the cumulus-induced vertical momentum transfers that act in a dominant way to oppose the thermal wind requirement and inhibit increase of vertical wind shear as baroclinicity increases. Vortex development thus requires a continual imbalance of pressure over wind acceleration (Gray, 1967).

To see the impact of cumulus parameterization schemes on the wind shear and thus on the intensification, time series 


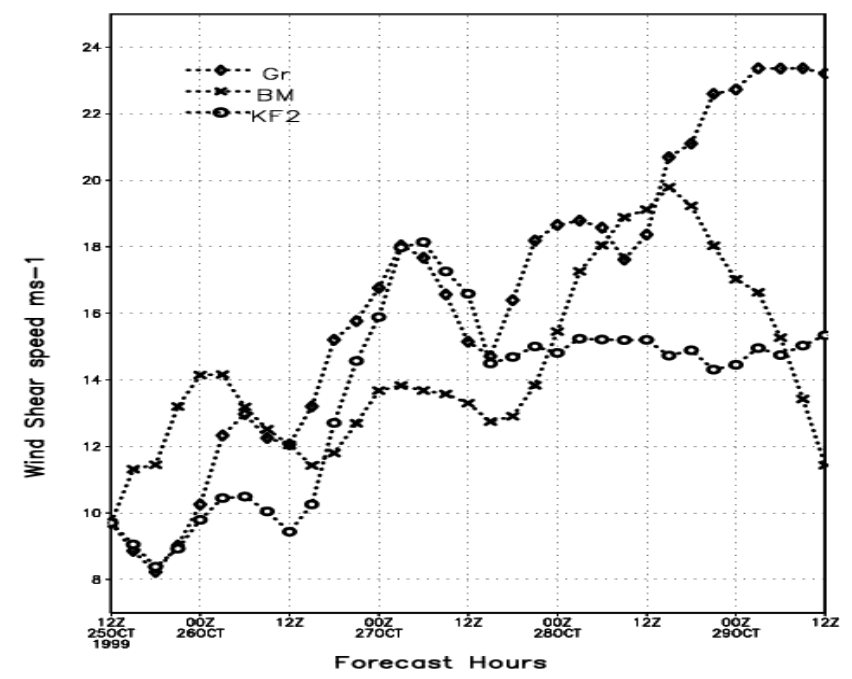

Fig. 4. Time series from 0 to $96 \mathrm{~h}$ of integration (that is from 12:00 UTC, 25 to 12:00 UTC, 29 October 1999) of domainaveraged vertical wind shear $\left(\mathrm{m} \mathrm{s}^{-1}\right)$ of horizontal wind between 850 and $200 \mathrm{hPa}$ levels.

of domain-averaged, vertical wind shear (between 850 and $200 \mathrm{hPa}$ layers) of horizontal wind is plotted in Fig. 4. As observed by Frank and Ritchie (2001), there was a time lag between the imposition of the shear and the resulting change in the minimum central pressure of the simulated storms. From Fig. 4, during initial $24 \mathrm{~h}$ of integration (up to 12:00 UTC, 26 October), the intensity is same for all three schemes, but shear is weak for KF2 (ranging from $8-11 \mathrm{~m} \mathrm{~s}^{-1}$ ) compared to Gr and BM simulated storms. The weak shear at the initial development stage of the storm might have helped the further development of the KF2 simulated storm, whereas for $\mathrm{Gr}$ and BM simulated storms, high shear during initial $24 \mathrm{~h}$ of integration might have hampered further intensification. Observational studies suggest that a TC cannot develop unless environmental, vertical wind shear is below a certain threshold value, which is found to be approximately $12.5 \mathrm{~m} \mathrm{~s}^{-1}$ between 850 and $200 \mathrm{hPa}$ layers in the western North Pacific and $8-10 \mathrm{~m} \mathrm{~s}^{-1}$ in the Atlantic (Zehr, 1992; Gallina and Velden, 2002; Ritchie, 2002). However, evidence also shows that well-developed TCs can survive quite large vertical shear conditions (e.g. $15-20 \mathrm{~m} \mathrm{~s}^{-1}$ ) over the western North Pacific (Wang and Wu, 2004; Zeng et al., 2007). Since the KF2 storm was well-developed, it could sustain and intensify further, though the shear is increasing from $9.5 \mathrm{~m} \mathrm{~s}^{-1}$ to $18 \mathrm{~m} \mathrm{~s}^{-1}$ during 24-42 $\mathrm{h}$ of integration (12:00 UTC of 27 to 06:00 UTC of 28 October 1999). After, $42 \mathrm{~h}$ shear is decreasing and is almost constant (about $15 \mathrm{~m} \mathrm{~s}^{-1}$ ) from 48 to $90 \mathrm{~h}$ of integration, during which KF2 storm rapidly intensified, reached its maximum intensity and maintained it. BM has a rapid fall of wind shear after 80-90 h of forecast; still, intensity is decreasing, because it is near the coast (BM landfall is at $84 \mathrm{~h}$ of integration).
The inner-core rainfall of storms is a good indicator of the latent heat release, which is a crucial heat source for intensification. Rodgers et al. (1994a, b) showed examples that the strength of northwest Pacific typhoon intensity is significantly correlated with rainfall intensity within the inner cores (radius of $110 \mathrm{~km}$ from storm centre) of the typhoon. The case studies of Hurricane Isidore and Lili (2002) (Jiang et al., 2008) demonstrated that the inner-core mean rain rate peaks (convective bursts) appear to proceed the times of maximum surface winds. This inner-core rain peak and intensity relationship was also revealed in satellite and aircraft observation studies of Typhoon Lynn (1987) (Rao and MacArthur, 1994), Typhoon Bobbie (1992) (Rodgers and Pierce, 1995), Hurricane Opal (1995) (Rodgers et al., 1998), Typhoon Paka (1997) (Rodgers et al., 2000), and Hurricane Bonnie (1998) (Heymsfield et al., 2001), as well as in observational studies of Hurricane Daisy (1958) (Riehl and Malkus, 1961) and tropical Cyclone Oliver (1993) (Simpson et al., 1998). The simulated rain per $3 \mathrm{~h}$ is plotted in Fig. 5 for the three CPS during rapid intensification stage and mature stage (60-96 h) along with that obtained from the Tropical Rainfall Measuring Mission (TRMM) data. In this study the 3B42 version 6 product is used (Huffman et al., 2007). The data set is available over the regions between $50^{\circ} \mathrm{N}$ to $50^{\circ} \mathrm{S}$, with a spatial resolution of $0.25^{\circ} \times 0.25^{\circ}$, with outputs at $3 \mathrm{~h}$ intervals.

It can be seen from Fig. $5 \mathrm{a}-\mathrm{c}$ that during rapid intensification phase $(60-84 \mathrm{~h})$ the rainfall is intense $(27-30 \mathrm{~cm})$ and is concentrated in the core of the storm. Gr overestimates the areal coverage of the light rain $(<3 \mathrm{~cm})$, but the rain rate in the core of the storm is comparatively less $(<18 \mathrm{~cm})$, which leads to weak storm (Fig. 5e-h). For BM simulated storm, rain rate in the core increases during 60 to $84 \mathrm{~h}$ (Fig. 5i-k). The maximum rain in the core is $<21 \mathrm{~cm}$ at $84 \mathrm{~h}$ of integration. The KF2 storm, which has simulated the rapid intensification phase, also simulates the maximum rain $(27-30 \mathrm{~cm})$ in the core (Fig. 5m-o), comparable with the observed rain (TRMM 3B42).

All these results show that the simulated track, intensity, precipitation patterns are sensitive to CPS. Only KF2 could simulate the rapid intensification and final intensity comparable with observation. A similar result is obtained by Davis and Bosart (2002) in the case of rapid intensification of Hurricane Diana (1984). The reason for better performance of KF2 scheme may be due to inclusion of updrafts and downdrafts. Also, the trigger function in the Kain-Fritsch scheme includes a buoyancy contribution, which is positive if there is grid-resolved upward motion at the lifted condensation level (Fritsch and Kain, 1993). Other schemes simply check for buoyancy by lifting parcels representative of individual layers. Given that widespread upward motion is induced by convergence and the initial presence of minimal convective inhibition, the Kain-Fritsch scheme becomes widely active. The Kain-Fritsch scheme is effective in stabilizing the lower troposphere to parcel ascent, but maintains marginal conditional instability for lifted layers (Davis and Bosart, 2002). 
(a) TRMM 60hrs

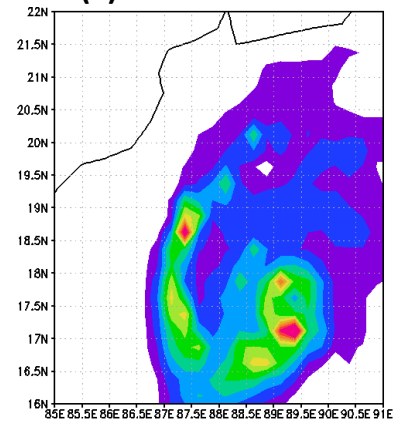

(e) Gr 60hrs

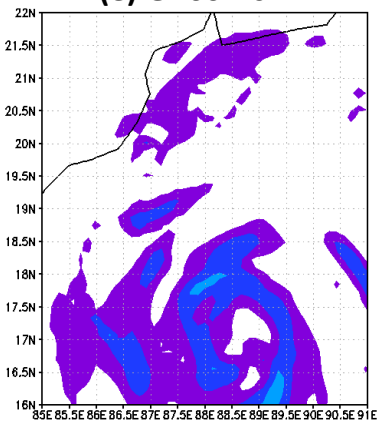

(i) BM 60hrs

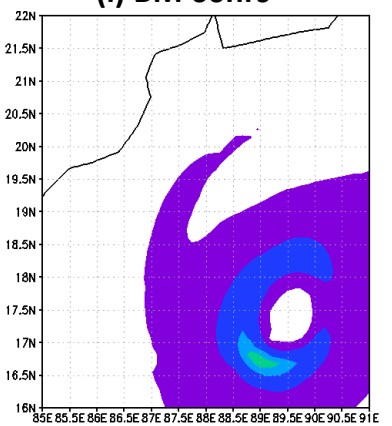

(m) KF2 60hrs

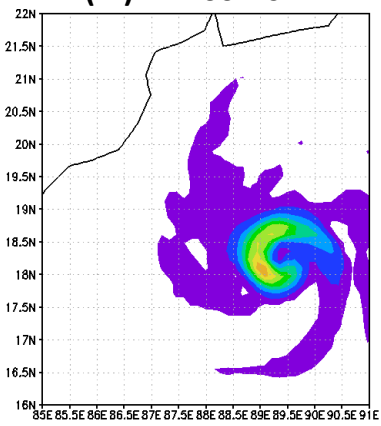

(b) TRMM 72hrs

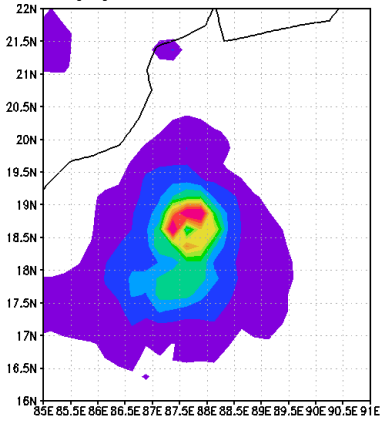

(f) Gr 72hrs

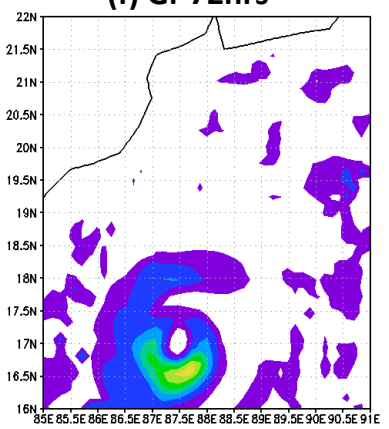

(j) BM 72hrs

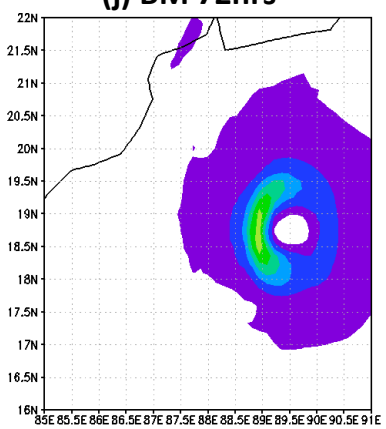

(n) KF2 72hrs

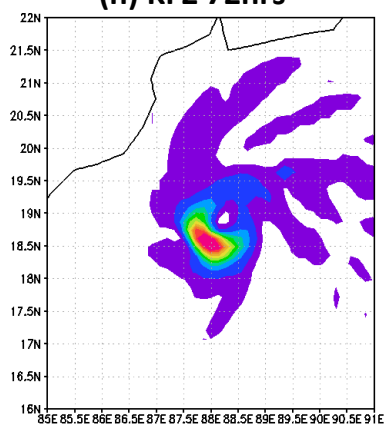

(c) TRMM 84hrs

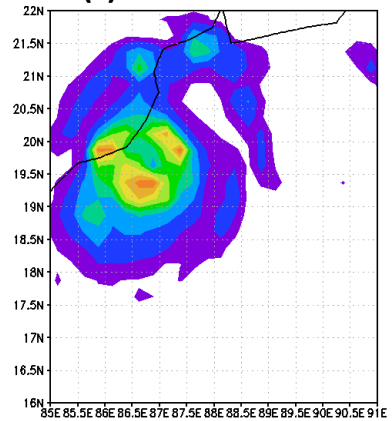

(g) Gr 84hrs

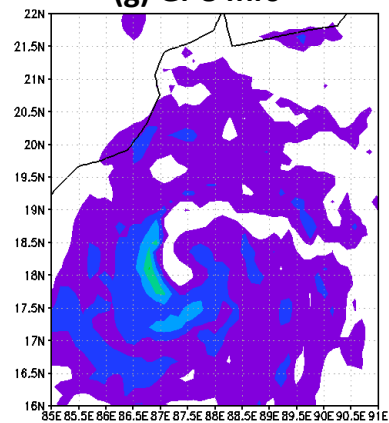

(k) BM 84hrs

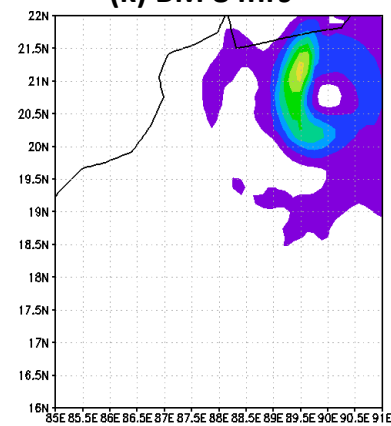

(o) KF2 84hrs

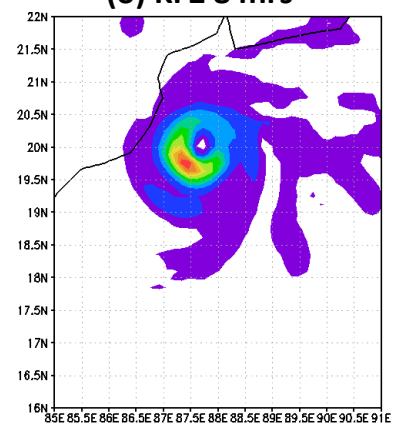

(d) TRMM 96hrs

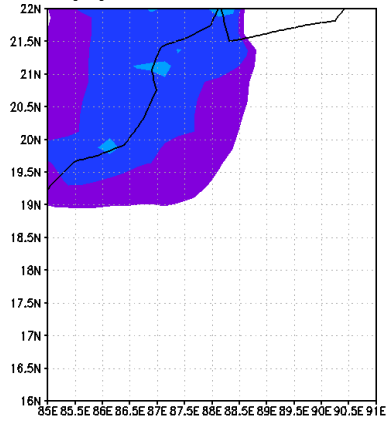

(h) Gr 96hrs

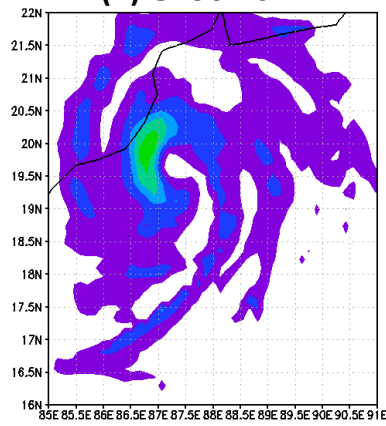

(I) BM 96hrs

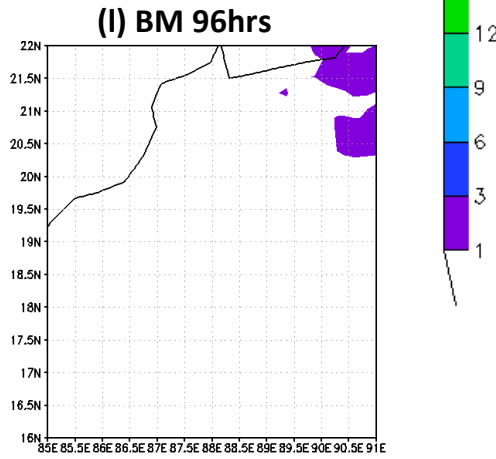

(p) KF2 96hrs

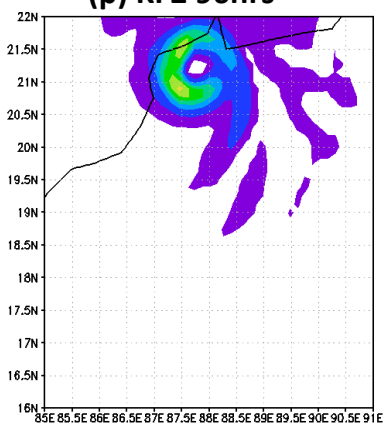

Fig. 5. Rain accumulated (mm) in $3 \mathrm{~h}$ obtained from TRMM (a)-(d) data and as simulated by model with three CPS, namely Gr (e)-(h), BM (i)-(l) and KF2 (m)-(p) during 60-96 h of integration (that is from 00:00 UTC, 28 to 12:00 UTC, 29 October 1999).

BM failed to simulate the observed track and intensity evolution may be mainly because of the limitation of no environmental feedback below the cloud base (Rao and Prasad, 2006). The BM has the highest track error out of the three CPSs. The downdrafts are included in Grell scheme, but it does not activate enough to suppress grid-scale overturning, thus simulating a weak storm. It is seen that the CPS of KF2 could simulate the track and intensity both comparable to the observed one; further experiments are conducted considering $\mathrm{KF} 2$ as CPS. 
a

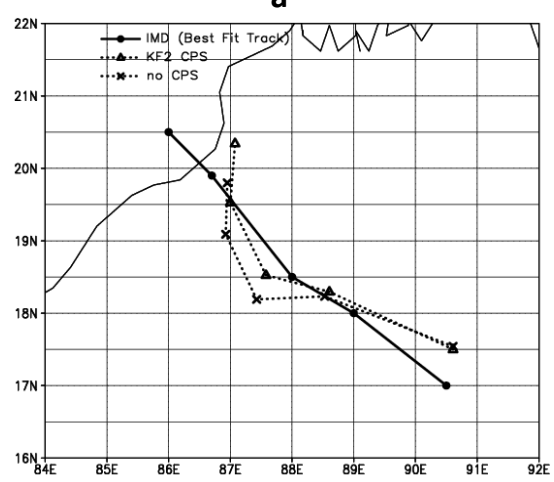

b

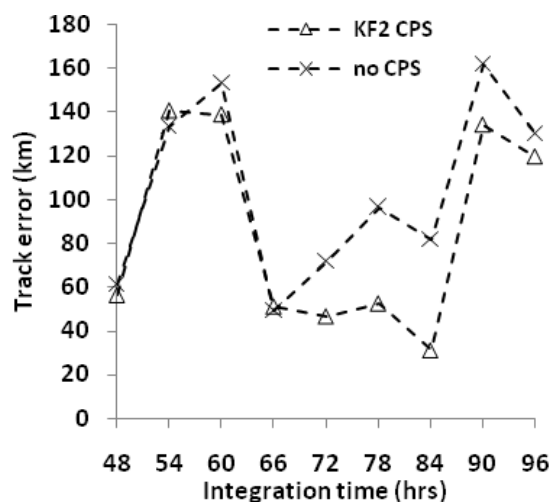

c

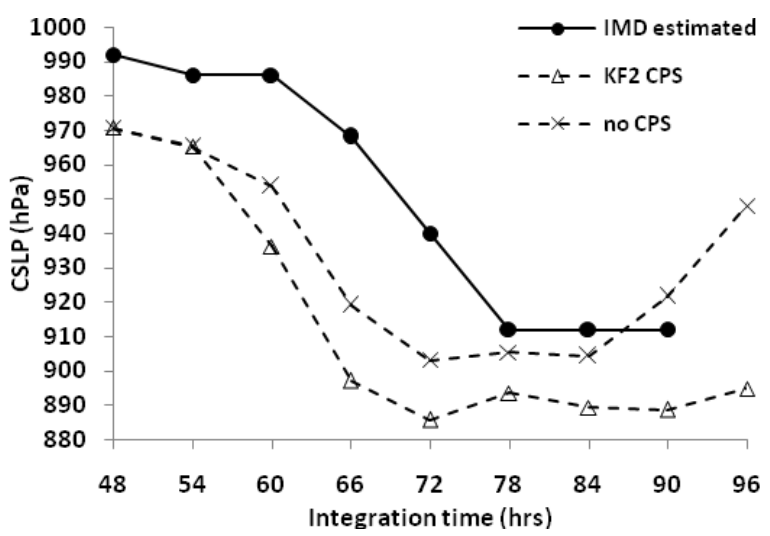

d

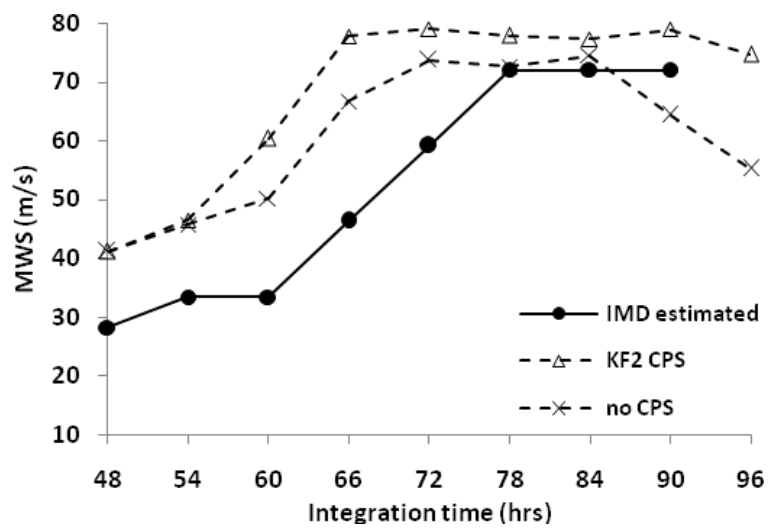

Fig. 6. Same as Fig. 2 but for the experiments of sensitivity to explicit modelling of convection: with CPS of KF2 and without any CPS in the D3 with three-domain configuration $(45,15,5 \mathrm{~km}$ resolution).

\subsection{Impact of explicit modelling of convection in the high resolution $(5 \mathrm{~km}$ resolution)}

As progressively smaller grid spacing is used in numerical modelling of mesoscale weather systems, explicit simulation of convection without parameterization has become more common. However, to our knowledge, the appropriateness of omitting the cumulus parameterization $(\mathrm{CP})$ scheme at smaller grid spacing ( $5 \mathrm{~km}$ or less) has not been systematically determined in a tropical environment, particularly for tropical cyclones in north Indian Ocean. Here, two experiments are conducted using three domains configuration (4515-5): one is with and another is without CPS for D3 (5 km resolution). The rest of all configuration remains same as that of previous section, including PBL of MY and MPS of MP for all the three domains, along with the CPS of KF2 for two domains (D1 and D2). The results in terms of track and intensity are presented in Fig. 6 . The improvement in the track and intensity forecast due to inclusion of third domain with $5 \mathrm{~km}$ resolution is noted, compared to that of with two domain experiments in the previous section. In the Fig. 6 "KF2 CPS" stands for the implicit simulation with KF2 parameterization scheme and "no CPS" implies explicit simulation with "no parameterization" scheme for D3 (5 km resolution). Domain D3, on which this experiment is carried out, is started after $48 \mathrm{~h}$ of integration; therefore, the results are presented after $48 \mathrm{~h}$. The development of tropical cyclone can be simulated by excluding the cumulus parameterization. The cumulus parameterization scheme has minimal impact on the track, but intensity forecast varies as much as $18 \mathrm{hPa}$ in these two experiments at the grid resolution of $5 \mathrm{~km}$. Comparing the intensity variation it can be seen that a storm with CPS is more intense than that without CPS. Baik et al. (1990) also reported that the model storm with the explicit latent heat release is considerably less intense than that with parameterized convective latent heat release. Maximum intensity is better predicted by "no CPS" experiments $(903 \mathrm{hPa}$ and $\left.74 \mathrm{~m} \mathrm{~s}^{-1}\right)$ compared to KF2 CPS $\left(885 \mathrm{hPa}\right.$ and $\left.79 \mathrm{~m} \mathrm{~s}^{-1}\right)$ at 12:00 UTC of 28 October 1999, which overpredicts the intensity.

The simulated rain per $3 \mathrm{~h}$ is plotted in Fig. $7 \mathrm{a}-\mathrm{h}$ for these two experiments, which can be compared with that of 
(a) 'KF2 CPS' 60hrs

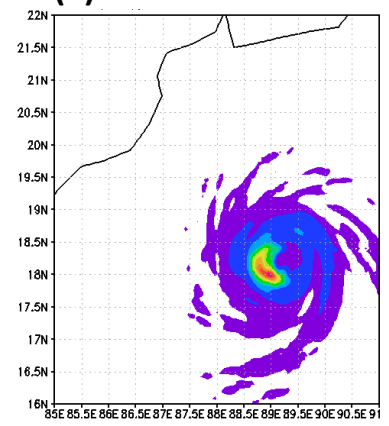

(e) 'No CPS' 60hrs

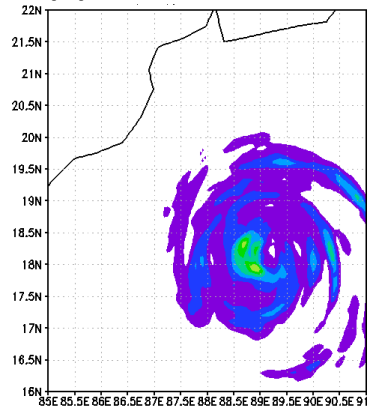

(b) 'KF2 CPS' 72hrs

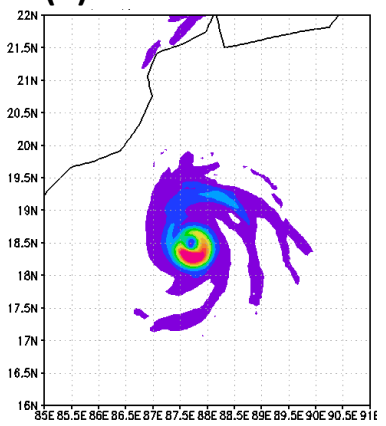

(f) 'No CPS' 72hrs

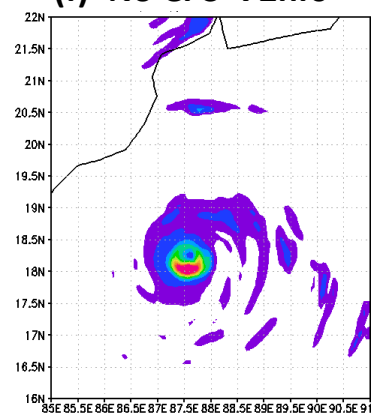

(c) 'KF2 CPS' 84hrs

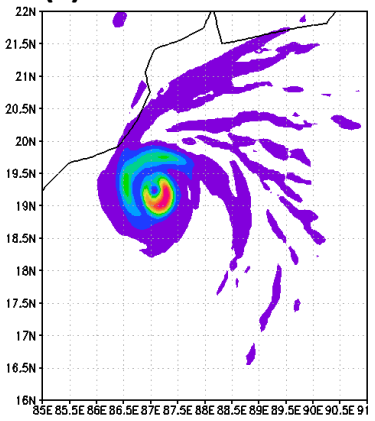

(g) 'No CPS' 84hrs

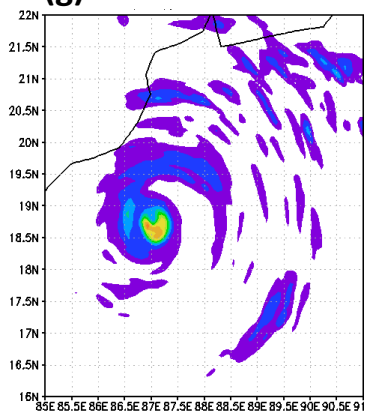

(d) 'KF2 CPS' 96hrs

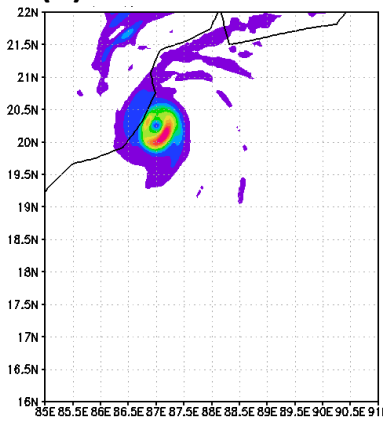

(h) 'No CPS' 96hrs

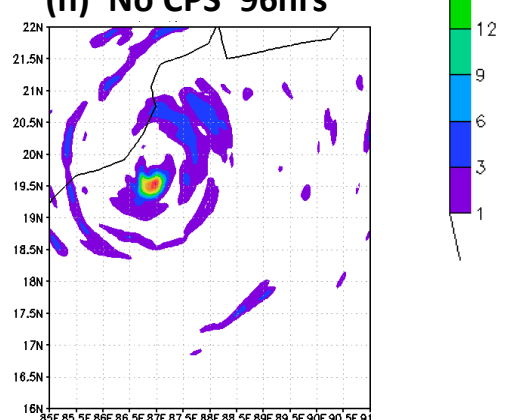

Fig. 7. Same as Fig. 5 but for the experiments of sensitivity to explicit modelling of convection: (a)-(d) with CPS of KF2 and (e)-(h) without any CPS in the D3 with three-domain configuration $(45,15,5 \mathrm{~km}$ resolution).

TRMM plotted in Fig. 5a, b, c and d at 60, 72, 84 and $96 \mathrm{~h}$ of integration. Though intensity is overestimated when both cumulus and explicit schemes are used together in the model, it could be able to produce better characteristics of storm organization structure, such as improved eyewall and rain bands features.

During the cyclone evolution, the intensity and track forecast depends largely on the evolution and distribution of the heating rates (Wu and Wang, 2001; Wang, 2009), which is mostly decided by the release of latent heat by the condensate within the system. To examine the associated vertical heating profiles that play an important role in determining intensification, diabatic heating rate $(\mathrm{d} \theta / \mathrm{d} t)$ is calculated. Time evolution of the $\mathrm{d} \theta / \mathrm{d} t$ and frozen hydrometeors averaged over the square area $\left(1^{\circ} \times 1^{\circ}\right)$ in the storm core is shown in Figs. 8 and 9 , respectively. Both the experiments show maximum heating at 500-200 $\mathrm{hPa}$ layer throughout the integration period. Overall heating rate is more after $60 \mathrm{~h}$ of integration (00:00 UTC, 28 October) for KF2 CPS experiment, which gives an intense storm (by $18 \mathrm{hPa}$ ). More heating for KF2 CPS experiment may be a consequence of condensation due to more frozen hydrometeors compared to "no CPS" experiment, as seen from Fig. 9.

Figure 10 shows the vertical cross section of the tangential wind speed during rapid intensification of the storm. Without the convective parameterization, the tangential wind decreases rapidly with height above the $500 \mathrm{mb}$ level. When the convective heating is included, the tangential wind decreases more slowly with height, so that tangential winds exceeding $30 \mathrm{~m} \mathrm{~s}^{-1}$ extend up to about $150 \mathrm{mb}$. Baik et al. (1990) also obtained similar variation of tangential wind in the study of impact of explicit parameterization scheme.

\section{Sensitivity to cloud microphysics parameterization schemes (MPS)}

Sensitivity experiments with respect to explicit moisture processes are performed in combination with KF2 and MY parameterization schemes for convection and PBL processes, respectively for all the domains except "no CPS" for D3, because this combination produced the best simulation of track and intensity in the previous experiments. Along with the previous experiment with MPS of mixed phase (MP), three more simulation experiments are performed with the options for explicit moisture processes, as Goddard Graupel (GG), Reisner Graupel (RG) and Schultz (Sc). Here, we would like to mention that the experiment with the MPS of MP is the same as the experiment of "no CPS" mentioned in Sect. 3.1. Forecast track, track error and time variation of CSLP and MWS are shown in Fig. 11a-d. The observed storm moved almost in the northwestward direction. The simulated tracks are northwestward, up to about $78 \mathrm{hrs}$ of integration (i.e. 18:00 UTC, 28 October 1999) and there is a bias towards north in the forecast tracks by all four MPS. The track error is comparable for all the schemes up to $12 \mathrm{~h}$ of integration and thereafter the difference increases. Throughout the 
Table 1. Overview of MM5 model configuration for the experiments of sensitivity to the cumulus parameterization schemes (CPS) and microphysics parameterization schemes (MPS).

\begin{tabular}{ll}
\hline Initial and lateral boundary condition data & ERA-40 \\
\hline Number of domains & $\begin{array}{l}\text { Two (D1 and D2 for CPS experiments), three (D1, D2 and D3 for MPS } \\
\text { experiments) }\end{array}$ \\
\hline Central point of domain D1 & $15^{\circ} \mathrm{N}, 88^{\circ} \mathrm{E}$ \\
\hline Horizontal grid distance & D1 $-45 \mathrm{~km}, \mathrm{D} 2-15 \mathrm{~km}, \mathrm{D} 3-5 \mathrm{~km}$ \\
\hline No. of horizontal grid points in X \& Y-direction & D1 - 110 $\times 110$ \\
& D2 $-154 \times 154$ \\
& D3 - 226 $\times 202$ \\
\hline Period of integration & D1 from 12:00 UTC, 25 to 12:00 UTC 29 Oct 1999 \\
& D2 from 12:00 UTC, 26 to 12:00 UTC, 29 Oct 1999 \\
D3 from 12:00 UTC, 27 to 12:00 UTC 29 Oct 1999 \\
\hline Time step & $120 \mathrm{~s}, 40 \mathrm{~s}, 13.33 \mathrm{~s}$ \\
\hline Microphysics parameterization schemes (MPS) & MP, GG, RG, Sc \\
\hline Cumulus parameterization schemes (CPS) & Gr, BM, KF2 \\
\hline PBL parameterization scheme (PBL) & MY \\
\hline Radiation parameterization scheme & CCM2 \\
\hline Soil model & Multi-layer soil thermal diffusion model \\
\hline Number of experiments conducted & 8 \\
\hline
\end{tabular}

a) KF2 CPS

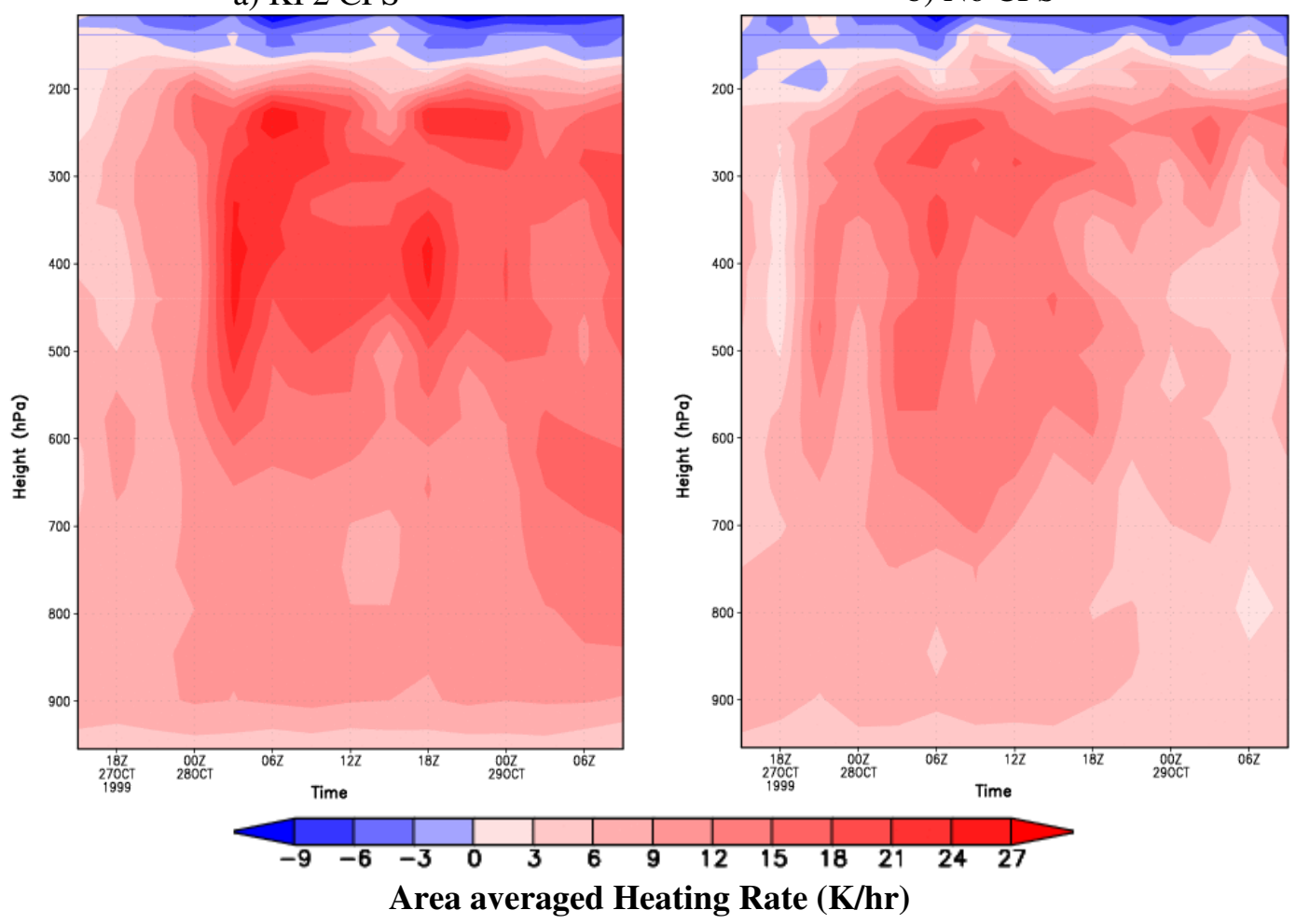

Fig. 8. Time-height cross section of heating rate $(\mathrm{d} \theta / \mathrm{d} t)$ in $\mathrm{K} / \mathrm{h}$, averaged over the square area of $1^{\circ} \times 1^{\circ}$, in the storm core with $($ a) $\mathrm{KF} 2$ CPS and (b) no CPS in D3. 

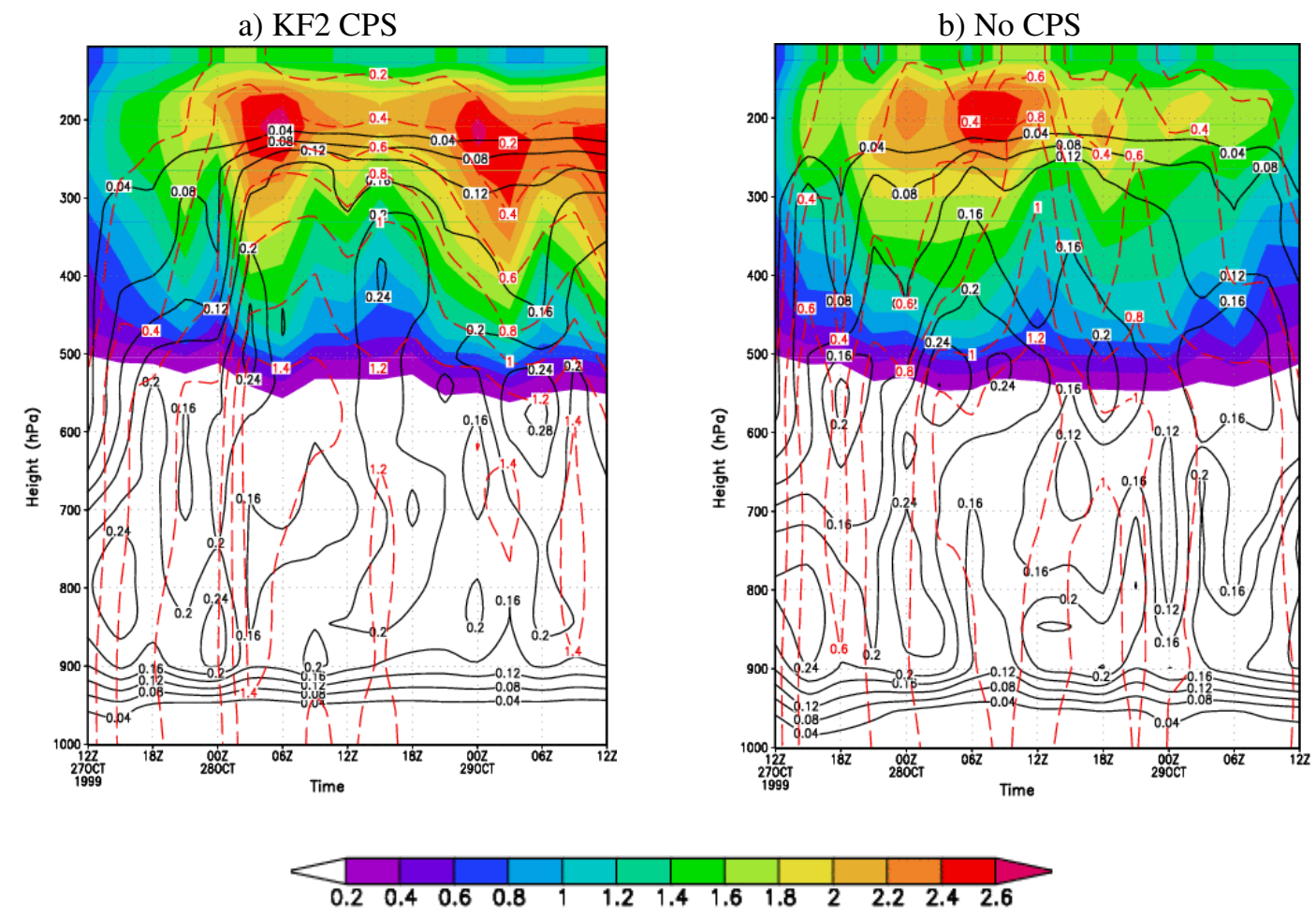

Fig. 9. Time-height cross section of hydrometeors mixing ratio in $\mathrm{gm} \mathrm{kg}^{-1}$ (frozen hydrometeors are shaded, liquid hydrometeors are solid contours for cloud water and dashed contours for rain water), averaged over the square area of $1^{\circ} \times 1^{\circ}$, in the storm core with (a) and without CPS (b) in D3.

(a) KF2 at $60 \mathrm{hrs}$

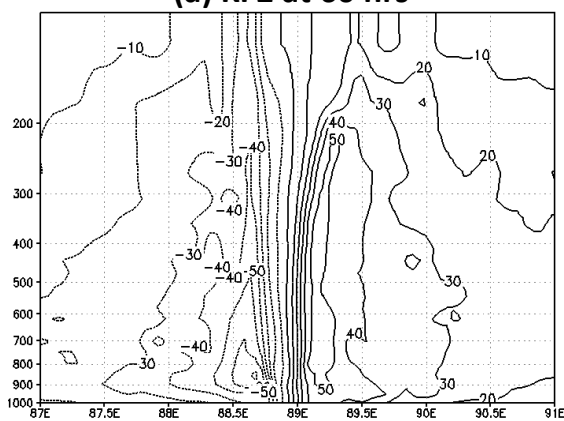

(d) No CPS at $60 \mathrm{hrs}$

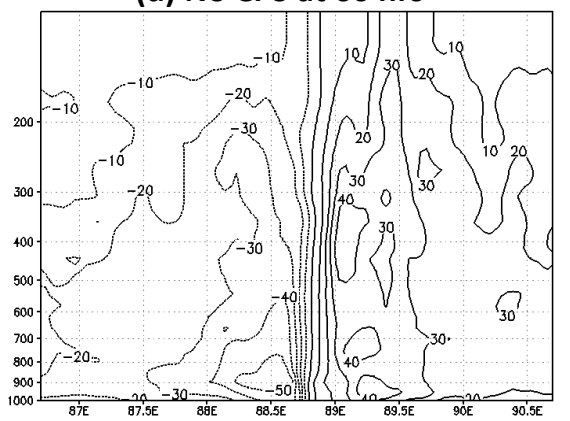

(b) KF2 72 hrs

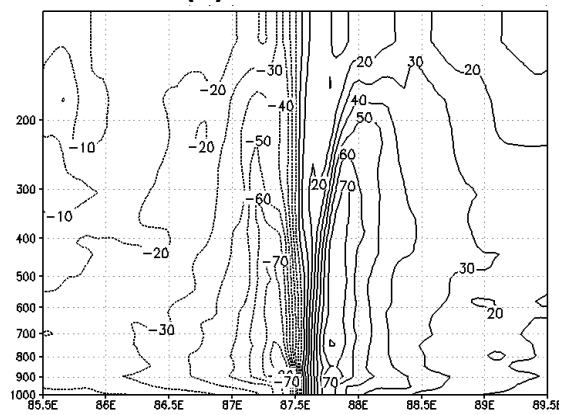

(e) No CPS at $72 \mathrm{hrs}$

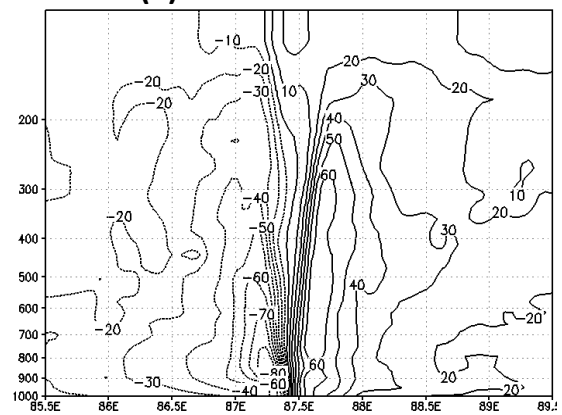

(c) KF2 84 hrs

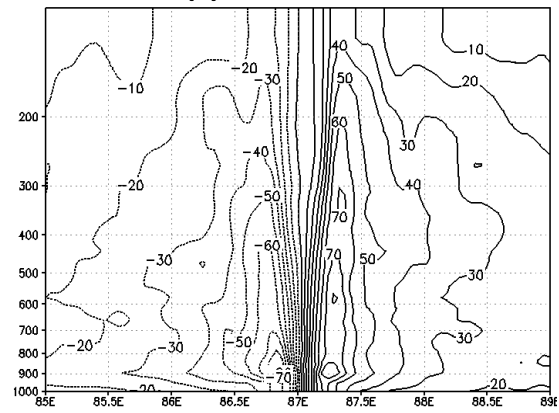

(f) No CPS at $84 \mathrm{hrs}$

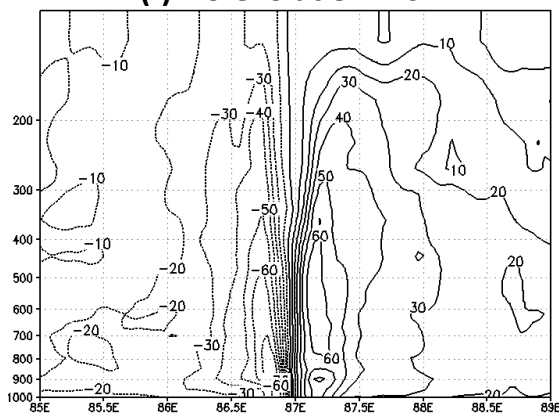

Fig. 10. Vertical cross section (passing through storm centre) of the tangential wind $\left(\mathrm{m} \mathrm{s}^{-1}\right)$ for (a)-(c) KF2 as CPS and (d)-(f) without any CPS in D3 at 60 (00:00 UTC of 28), 72 (12:00 UTC of 28) and 84 (00:00 UTC of 29 October 1999) h of integration. 
a

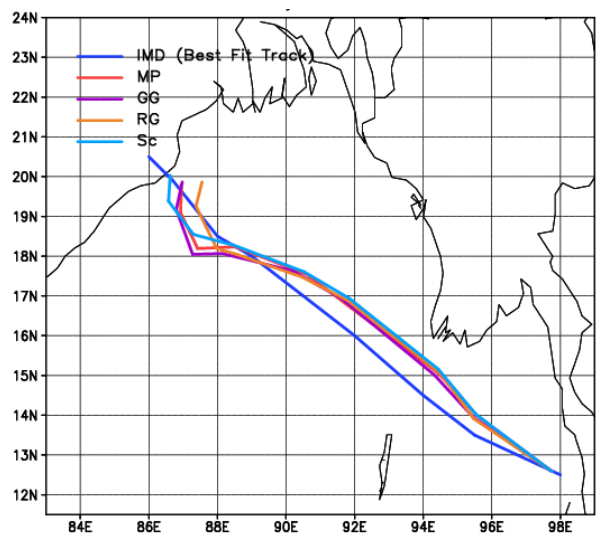

b

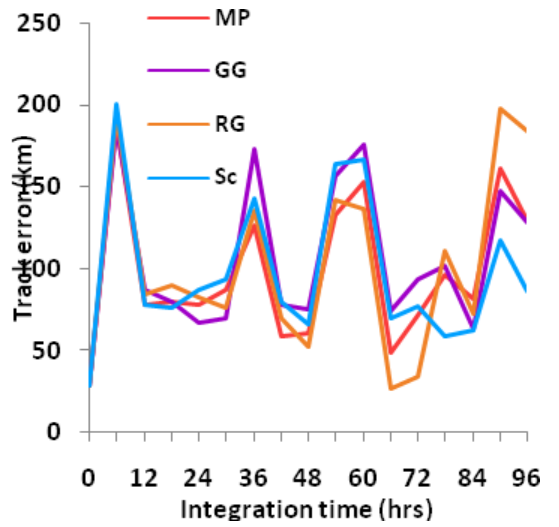

C

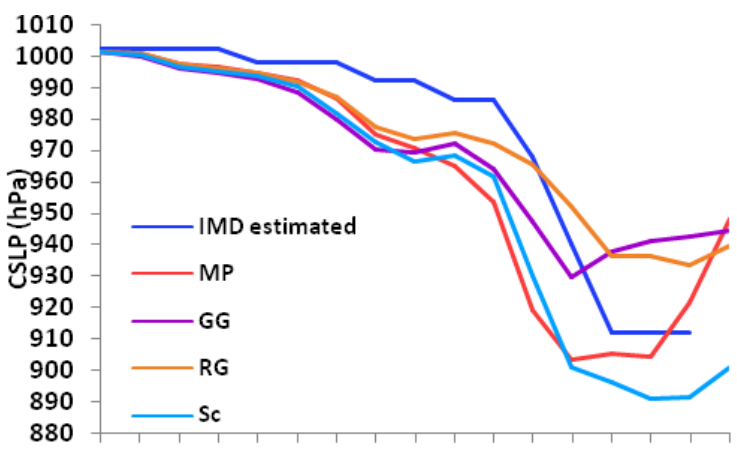

06121824303642485460667278849096 Integration time (hrs)

d

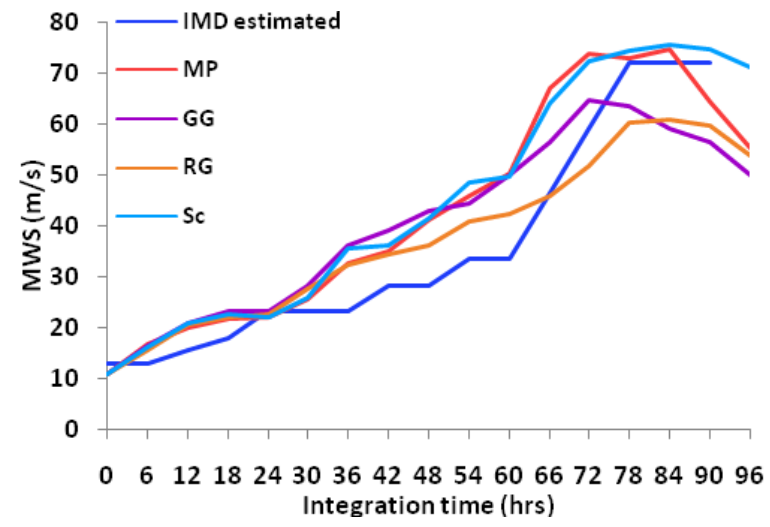

Fig. 11. Same as Fig. 6 but for the experiments with different MPS, namely MP, GG, RG and Sc.

Table 2. Simulated intensity values for MPS experiments on 18:00 UTC, 28 October 1999 when(as per the IMD estimate) the storm reached its maximum intensity $\left(912 \mathrm{hPa}, 72 \mathrm{~m} \mathrm{~s}^{-1}\right)$.

\begin{tabular}{ccccc}
\hline & MP & GG & RG & Sc \\
\hline CSLP & $905 \mathrm{hPa}$ & $938 \mathrm{hPa}$ & $937 \mathrm{hPa}$ & $896 \mathrm{hPa}$ \\
MWS & $73 \mathrm{~m} \mathrm{~s}^{-1}$ & $64 \mathrm{~m} \mathrm{~s}^{-1}$ & $60 \mathrm{~m} \mathrm{~s}^{-1}$ & $74 \mathrm{~ms}^{-1}$ \\
\hline
\end{tabular}

integration period the track error varies from $8 \mathrm{~km}$ to $223 \mathrm{~km}$ (Fig. 11a and b). Average track errors are $98 \mathrm{~km}, 105 \mathrm{~km}$, $101 \mathrm{~km}$ and $97 \mathrm{~km}$ for MP, GG, RG and Sc, respectively.

The simulated storms by GG and MP attained their minimum CSLPs of $930 \mathrm{hPa}$ and $910 \mathrm{hPa}$, respectively, both at 12:00 UTC, 28 October 1999. The storm obtained from Sc experiment reached its minimum CSLPs of $896 \mathrm{hPa}$ at 18:00 UTC, 28 October. The most delayed intensification occurred for RG storm. It reached its minimum CSLP of $934 \mathrm{hPa}$ at 06:00 UTC, 29 October. The maximum wind speed of the storm is $65 \mathrm{~m} \mathrm{~s}^{-1}$ (at 18:00 UTC, 28 October) for GG; $74 \mathrm{~m} \mathrm{~s}^{-1}, 61 \mathrm{~m} \mathrm{~s}^{-1}$ and $76 \mathrm{~m} \mathrm{~s}^{-1}$ for MP, RG and Sc, respectively (all at 06:00 UTC, 29). As per the IMD esti- mate, the observed minimum CSLP was $912 \mathrm{hPa}$ and MWS was $72 \mathrm{~m} \mathrm{~s}^{-1}$ at 18:00 UTC, 28 October 1999. The simulated intensity values for these MPS experiments on 18:00 UTC, 28 October are presented in Table 2.

The storms produced from GG and RG schemes underestimated the intensity. The intensity of the storm obtained from MP schemes is in close resemblance to the observed estimates. The experiment with Sc cloud microphysics parameterization scheme produced the most intense storm, but it somewhat overestimated the intensity. However, it very well captures the rapid deepening rate of CSLP (i.e. $3.7 \mathrm{hPa} \mathrm{h}^{-1}$ ) compared to that of the observed rate (i.e. $4.1 \mathrm{hPah}^{-1}$ ), in an interval of $18 \mathrm{~h}$ starting from 00:00 UTC to 18:00 UTC, 28 October 1999 . These results clearly demonstrate that the simulated tropical cyclone intensity and rate of intensification are significantly sensitive to the alteration of cloud microphysical schemes.

The rain accumulated in $3 \mathrm{~h}$ is plotted in Fig. 12 for the simulations with GG, RG and Sc schemes at 60, 72, 84 and $96 \mathrm{~h}$ of integration. This, along with the $3 \mathrm{~h}$ accumulated rain simulated with MP (plotted in Fig. 7e-h) can be compared with that of TRMM (Fig. 5a, b, c and d). Except Sc, all three microphysics schemes overestimate the spatial distribution 
(a) GG 60hrs

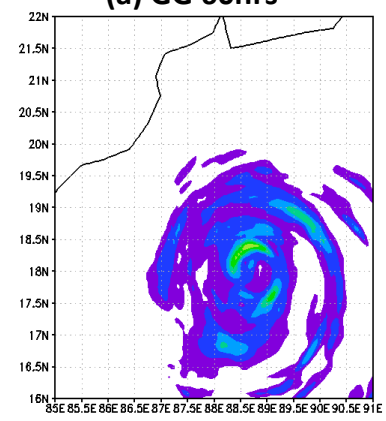

(e) RG 60hrs

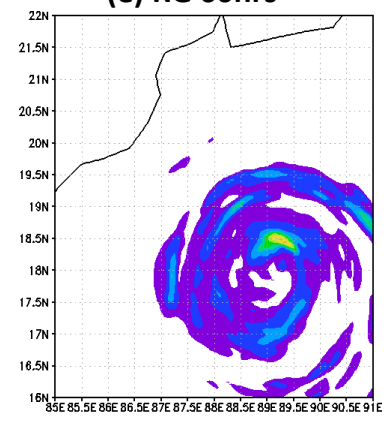

(i) Sc 60hrs

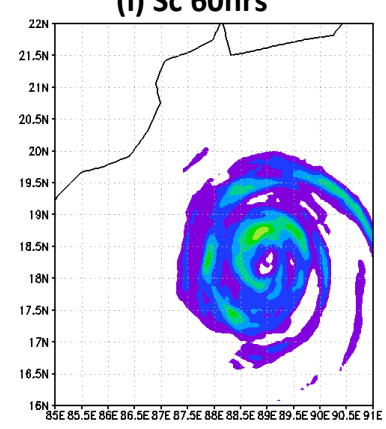

(b) GG 72hrs

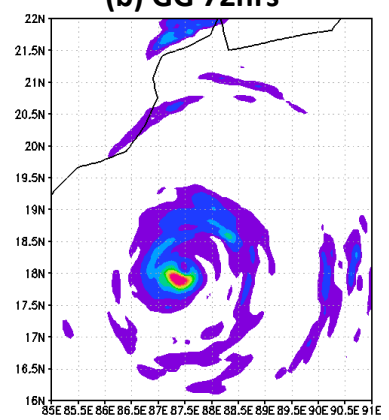

(f) RG 72hrs

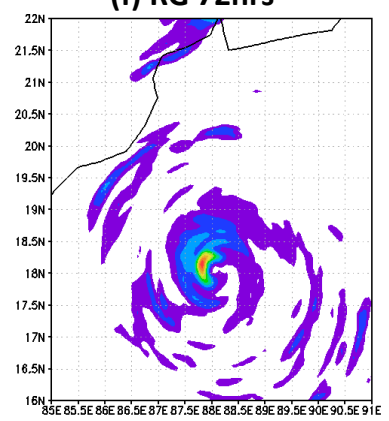

(j) Sc 72hrs

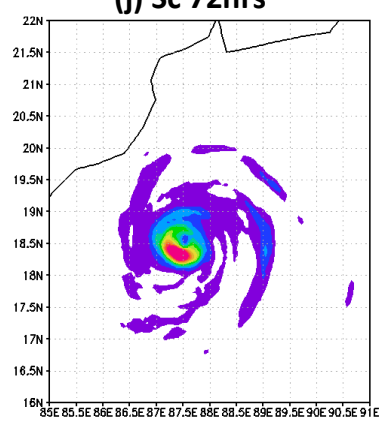

(c) GG $84 \mathrm{hrs}$

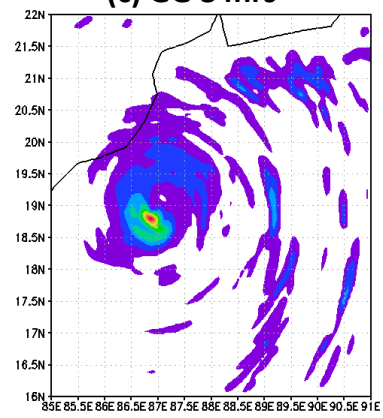

(g) RG $84 \mathrm{hrs}$

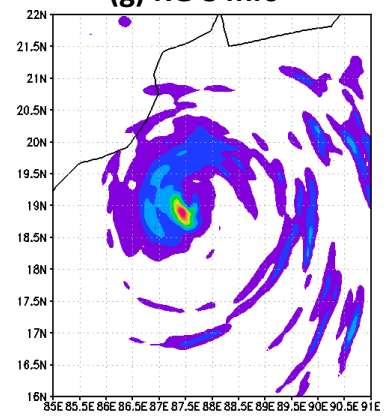

(k) Sc $84 \mathrm{hrs}$

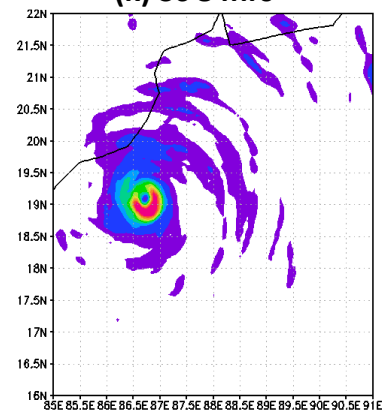

(d) GG 96hrs

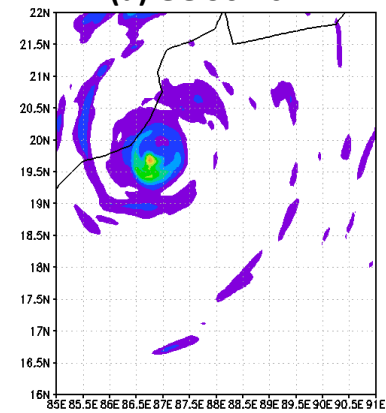

(h) RG 96hrs

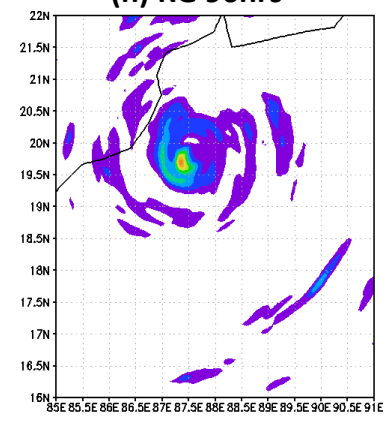

(I) Sc $96 \mathrm{hrs}$

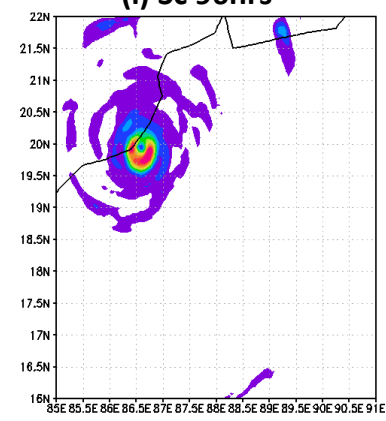

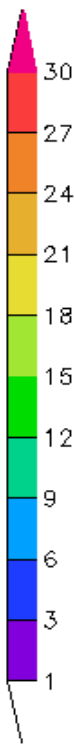

Fig. 12. Same as Fig. 5 but with three MPS, namely GG (a)-(d), RG (e)-(h) and Sc (i)-(l).

of light rain $(<3 \mathrm{~mm})$. Only Sc could simulate the spatial distribution of $3 \mathrm{~h}$ accumulated rain comparable with that of TRMM. It could simulate the spiral rain bands at $60 \mathrm{~h}$ and concentric eyewall at $72 \mathrm{~h}$, as seen in TRMM data (compare Fig. $11 \mathrm{~m}$ and $\mathrm{n}$ with Fig. 5a and b) during the rapid intensification phase of the storm.

Figure 13 displays the time-height plot of frozen hydrometeors obtained from different parameterization schemes viz. MP, GG, RG and Sc. It appears that, in the cases of GG and $\mathrm{RG}$ runs, large accumulation of frozen hydrometeors such as ice, snow and graupel in mid troposphere results in slowing down the vertical acceleration of the intense updrafts in the eye wall of the storm, which might be responsible for inhibiting the storm intensification. The water loading problem can occur due to one or a combination of factors, such as over production, reduction in vertical fall out rate and increase in horizontal advection of hydrometeors within the microphysical parameterization scheme. In the case of MP, GG and
RG runs, there is a large accumulation of hydrometeors in mid troposphere compared to the case of Sc run. Due to less hydrometeor loading in case of the storm obtained from Sc scheme, it has intense core of updrafts in the eyewall region (Fig. 14), which helps in latent heat release (warm core) and facilitating its intensification. The formulation of fall speed of frozen hydrometeors in Schultz scheme depends on the concentration of condensate, thus facilitating faster descent of frozen particles. This rapid fall out of hydrometeor within the core helps in eroding water loading problem and intensifying the storm.

\section{Summary and conclusions}

The fifth-generation Pennsylvania State University-National Center for Atmospheric Research (PSU-NCAR) nonhydrostatic Mesoscale Model (MM5 Version 3.7) was used for the simulation of Orissa super cyclone (1999). 


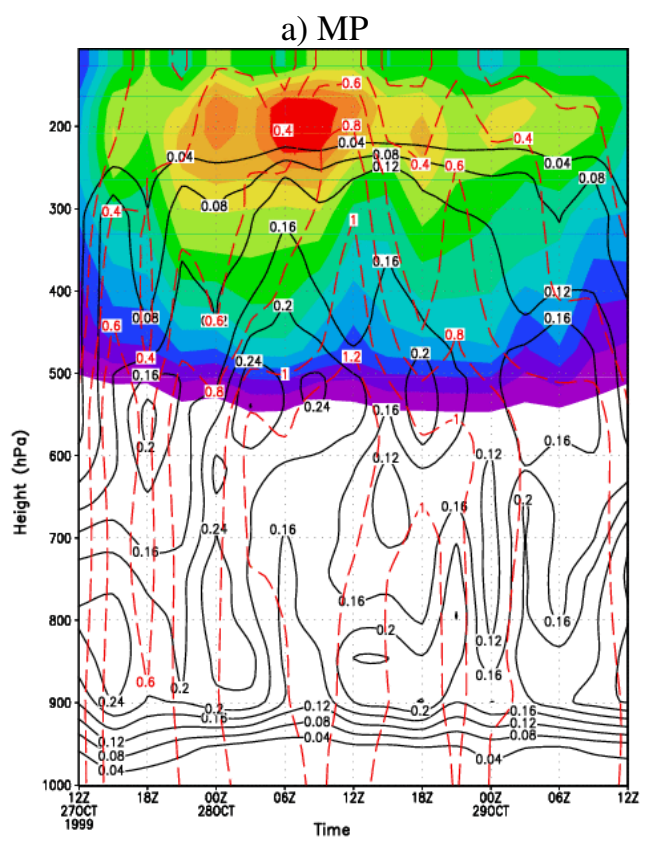

c) RG

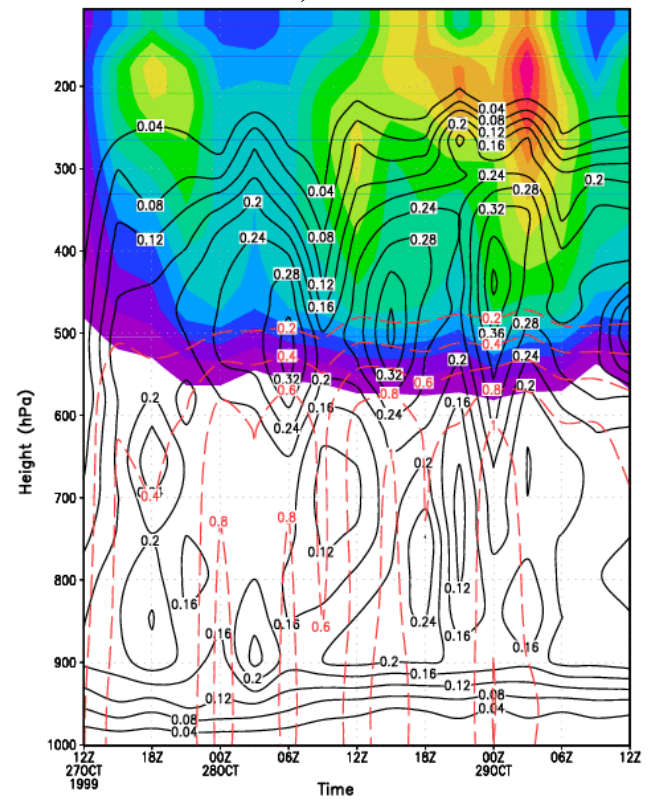

b) GG

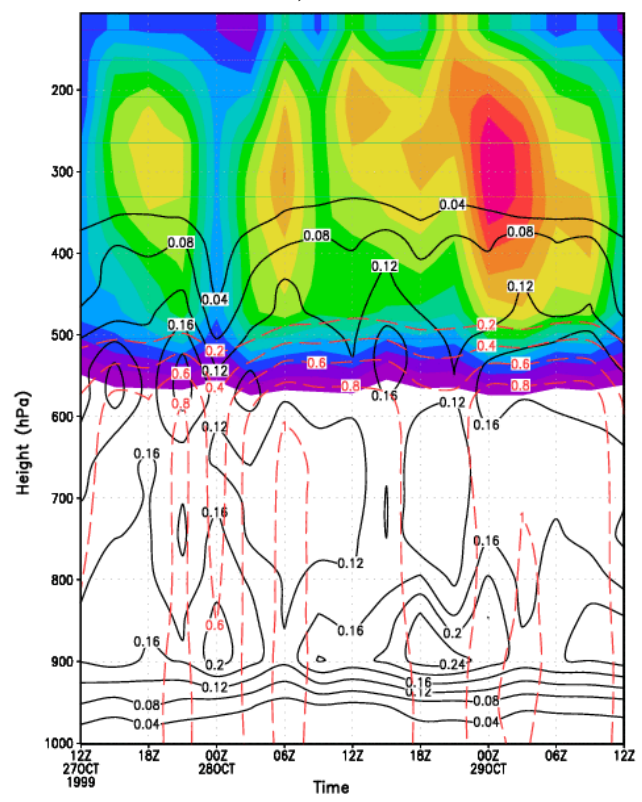

d) $\mathrm{Sc}$

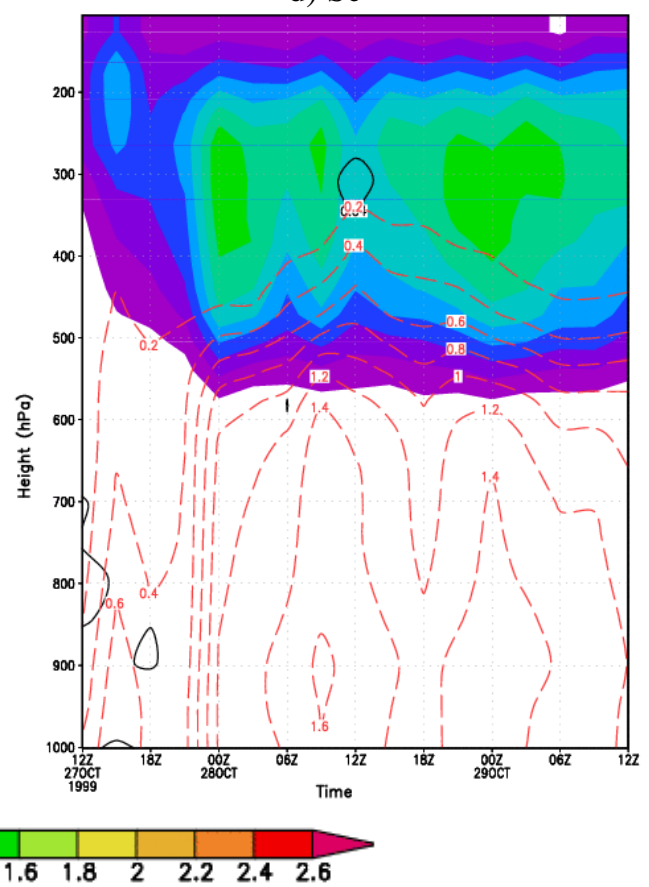

Fig. 13. Same as Fig. 8 but for the experiments with different MPS, namely (a) MP, (b) GG, (c) RG and (d) Sc.

Experiments were conducted to study the sensitivity of cloud parameterization schemes. All sensitivity experiments were integrated, starting from the tropical depression stage of the system at 12:00 UTC on 25 October 1999, through a stage of rapid intensification into a super cyclone (maximum surface wind of $72 \mathrm{~m} \mathrm{~s}^{-1}$ and central sea level pressure of $912 \mathrm{hPa}$ ) at 15:00 UTC on 28 October and finally to a stage, during which it maintained its intensity at 12:00 UTC on 29 October. Ini- tially, experiments were conducted by changing the cumulus parameterization schemes ( $\mathrm{Gr}, \mathrm{BM}$ and KF2) to see which one can simulate a realistic forecast of the track and intensity at the resolution of $15 \mathrm{~km}$. The CPS of KF is found to give a reasonably better track and intensity forecast. It has wellcaptured the rapid intensification and mature stages of the tropical cyclone, starting from a depression stage with weak vortex. The weak shear during developing stage of the storm 
a) MP

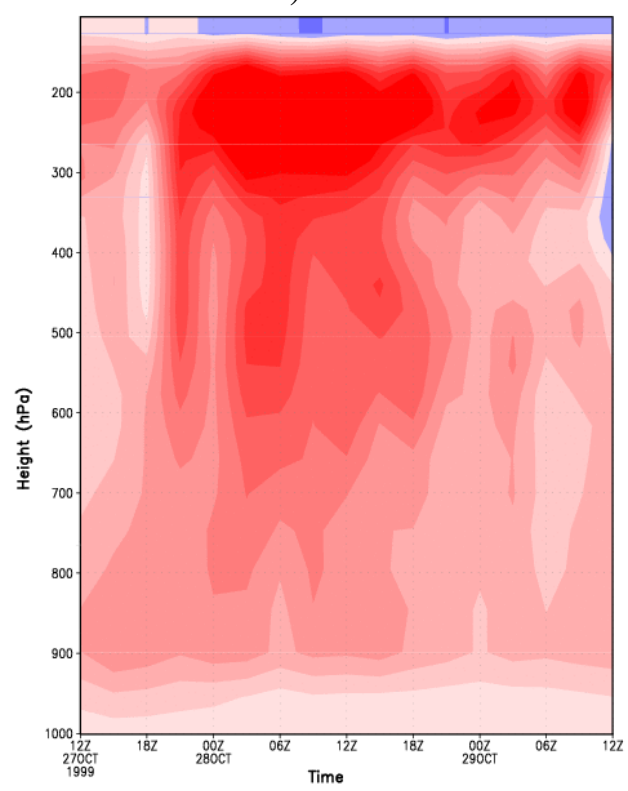

c) RG

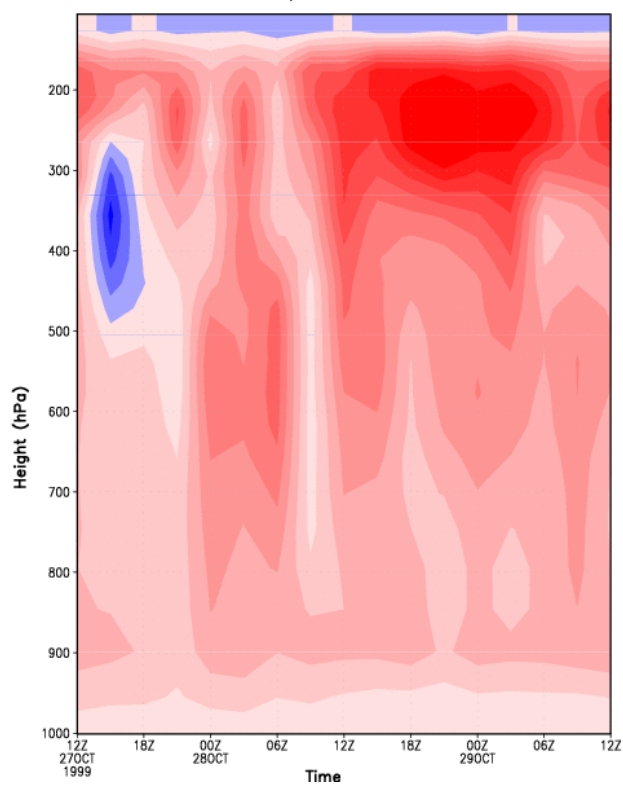

b) GG

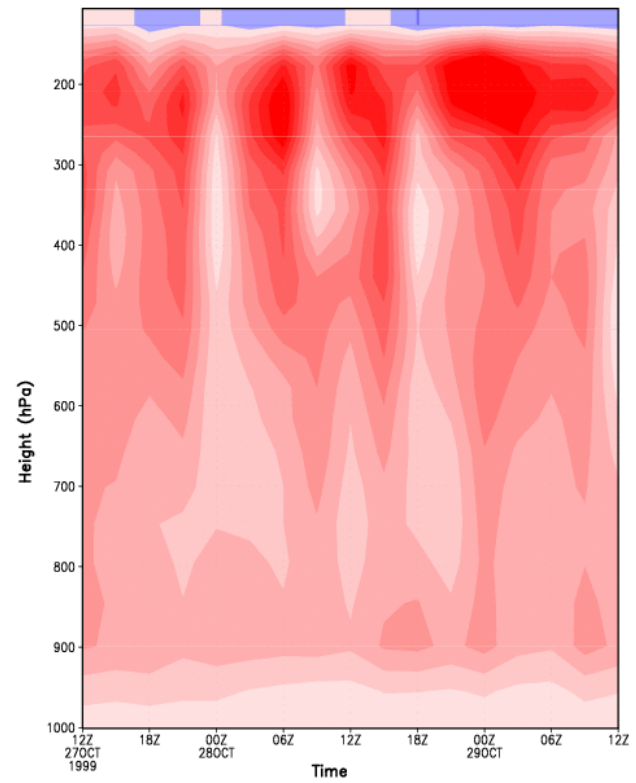

d) $\mathrm{Sc}$

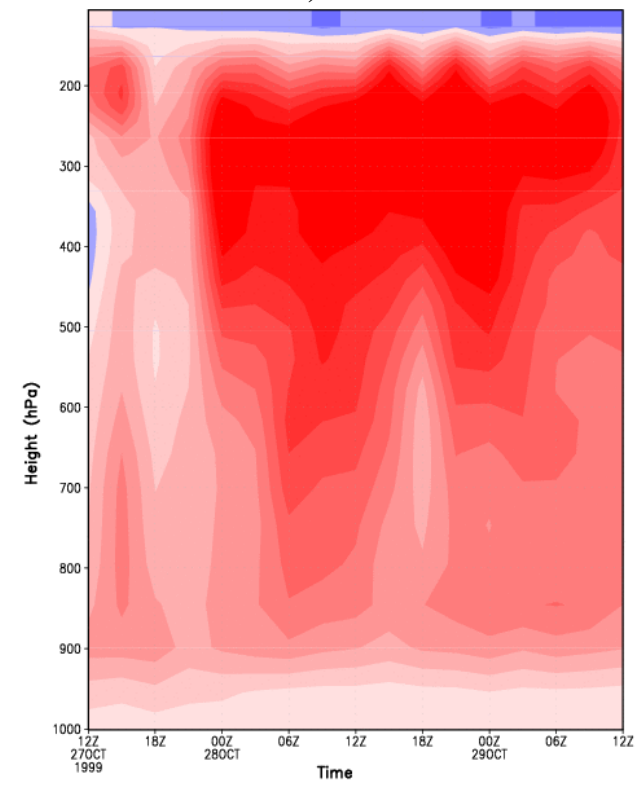

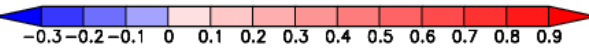

Fig. 14. Time-height cross section of vertical velocity in $\mathrm{m} \mathrm{s}^{-1}$, averaged over the square area of $1^{\circ} \times 1^{\circ}$, in the storm core for the experiments of different MPS, namely (a) MP, (b) GG, (c) RG and (d) Sc.

(in the initial $24 \mathrm{~h}$ of integration) might have helped the further fast intensification of KF2 simulated storm. Compared to $\mathrm{Gr}$ and $\mathrm{BM}, \mathrm{KF} 2$ could simulate the intense rain structure concentrated in the core of the storm and has a better agreement with the TRMM observations during the rapid intensification phase.

Generally, the cumulus parameterization is excluded at higher resolution. However, in this study we found that the cumulus parameterization scheme has significant impact on the track, distribution of rain and intensity of the storm, even at the grid resolution of $5 \mathrm{~km}$. In addition, we note that development of the tropical cyclone is reasonably simulated by the model without cumulus parameterization. The simulated track and intensity obtained from the experiment without CPS have close resemblances with the observations. It is found that the experiment with KF2 as a CPS in the D3 
overpredicts the intensity, because it produced more heating at the 500-200 hPa layer in the core as a consequence of large condensation due to more frozen hydrometeors, compared to "no CPS" experiment.

Further, the sensitivity to cloud microphysics parameterization schemes was carried out in a three-nested-domain configuration with "no CPS" in the third domain. The four different cloud microphysics parameterization schemes were tested, namely mixed phase (MP), Goddard microphysics with Graupel (GG), Reisner Graupel (RG) and Schultz microphysics (Sc). It is found that the tropical cyclone forecast tracks is less sensitive to MPS and are close to the observed track up to about $60 \mathrm{~h}$ of integration. Thereafter, there is a northward bias in all the simulated tracks. The most intense storm produced by Sc was the least bias. The storms produced from GG and RG schemes underestimated the intensity. The intensity of the storm obtained from MP schemes is in close resemblance to the observed estimates. The experiment with Sc cloud microphysics parameterization scheme produced the most intense storm, with the rainfall distribution comparable with TRMM data. Though Sc overestimated the intensity, it captures very well the rapid deepening rate of CSLP (i.e. $3.7 \mathrm{hPah}^{-1}$ ) compared to that of the observed rate (i.e. $4.1 \mathrm{hPah}^{-1}$ ) in an interval of $18 \mathrm{~h}$, starting from 00:00 UTC to 18:00 UTC, 28 October 1999. The storm obtained from Sc scheme has intense core of updrafts in the eyewall, maybe due to less hydrometers. Further work will be done in the near future in order to test the effectiveness of different microphysical parameters in the Sc.

These results clearly demonstrate that the simulated tropical cyclone intensity and rate of intensification are significantly sensitive to the alternation of cloud parameterization schemes. This study emphasizes the significance of NWP cloud parameterization schemes in simulating the track, intensity and rapid intensification of the tropical cyclones. The present study has investigated only one cyclone and more cases should be examined to supplement these results.

Acknowledgements. The authors thank the anonymous reviewers for their constructive comments, which have helped to improve the quality of the paper. The authors wish to thank the Director, Indian Institute of Tropical Meteorology (IITM), Pune for his encouragement and support. IITM is fully funded by the Ministry of Earth Sciences, Government of India, New Delhi. Authors acknowledge the use of MM5, which is made available on the Internet by the Mesoscale and Microscale division of NCAR. The use of ECMWF 40 year reanalysis (ERA-40) data and GrADS software is acknowledged with thanks.

Topical Editor P. Drobinski thanks two anonymous referees for their help in evaluating this paper.

\section{References}

Anthes, R. A.: A cumulus parameterization scheme utilizing a onedimensional cloud model, Mon. Weather Rev., 105, 270-286, 1977.
Arakawa, A. and Schubert, W. H.: Interaction of cumulus cloud ensemble with the large scale environment, Part I, J. Atmos. Sci., 31, 674-701, 1974.

Baik, J. J., DeMaria, M., and Raman, S.: Tropical cyclone simulations with the Betts convective adjustment scheme. Part I: Model description and control simulation, Mon. Weather Rev., 118, 513-528, 1990.

Baik, J.-J., DeMaria, M., and Raman, S.: Tropical cyclone simulations with the Betts convective adjustment scheme. Part III: Comparisons with the Kuo convective parameterization, Mon. Weather Rev., 119, 2889-2899, 1991.

Bender, M. A. and Ginis, I.: Real case simulations of hurricaneocean interaction using a high resolution coupled model: Effects on hurricane intensity, Mon. Weather Rev., 128, 917-946, 2000.

Betts, A. K.: A new convective adjustment scheme. Part I: Observational and theoretical basis, Q. J. Roy Meteorol. Soc., 112, 677$692,1986$.

Betts, A. K. and Miller, M. J.: A new convective adjustment scheme. Part II: Single column tests using GATE wave, BOMEX, ATEX, and Arctic air-mass data sets, Q. J. Roy Meteorol. Soc., 112, 693-709, 1986.

Betts, A. K. and Miller, M. J.: The Betts-Miller scheme. The representation of cumulus convection in numerical models, edited by: Emanuel, K. A. and Raymond, D. J., Amer. Meteor. Soc., 7246 pp., 1993.

Braun, S. A. and Tao, W. K.: Sensitivity of high-resolution simulations of hurricane Bob (1991) to planetary boundary layer parameterizations, Mon. Weather Rev., 128, 3941-3961, 2000.

Briegleb, B.: Delta-Eddington Approximation for Solar Radiation in the NCAR Community Climate Model, J. Geophys. Res., 97, 7603-7612, 1992.

Brown, P. R. A. and Swann, H. A.: Evaluation of key microphysical parameters in three-dimensional cloud-model simulations using aircraft and multiparameter radar data, Q. J. Roy. Meteorol. Soc., 123, 2245-2275, 1997.

Davis, C. A. and Bosart, L. F.: Numerical simulations of the genesis of Hurricane Diana (1984). Part II: Sensitivity of track and intensity prediction, Mon. Weather Rev., 130, 1100-1124, 2002.

DeMaria, M. and Kaplan, J.: Sea Surface Temperature and the maximum intensity of Atlantic Tropical Cyclones, J. Climate, 7, 1324-1334, 1994.

Deshpande, M. S., Pattnaik, S., and Salvekar, P. S.: Impact of physical parameterization schemes on numerical simulation of super cyclone Gonu, Natural Hazards, 55, 211-231, 2010.

Dudhia, J.: A nonhydrostatic version of the Penn State-NCAR mesoscale model: Validation tests and simulation of an Atlantic cyclone and cold front, Mon. Weather Rev., 121, 1493-1513, 1993.

Emanuel, K. A.: Tropical cyclone energetics and structure. Atmospheric Turbulence and Mesoscale Meteorology, edited by: Federovich, E., Rotunno, R., and Stevens, B., Cambridge University Press, pp. 165-192, 2004.

Fovell, R. G. and Su, H.: Impact of cloud microphysics on hurricane track forecasts, Geophys. Res. Lett., 34, L24810, doi:10.1029/2007GL031723, 2007.

Frank, W. M. and Ritchie, E. A.: Effects of Vertical Wind Shear on the Intensity and Structure of Numerically Simulated Hurricanes, Mon. Weather Rev., 129, 2249-2269, 2001. 
Fritsch, J. M. and Kain, J. S.: Convective parameterization for mesoscale models: The Fritsch-Chappel scheme. The Representation of Cumulus Convection in Numerical Models, Meteor. Monogr., No. 46, edited by: Emanuel, K. A. and Raymond, D. J., Amer. Meteor. Soc., 1993.

Gadd, A. J. and Keers, J. F.: Surface exchanges of sensible and latent heat in a 10-level model atmosphere, Q. J. Roy. Meteorol. Soc., 96, 297-308, 1970.

Gallina, G. M. and Velden, C. S.: Environmental vertical wind shear and tropical cyclone intensity change utilizing enhanced satellite derived wind information, Proceedings of the 25th Conference on Hurricanes and Tropical Meteorology, 29 April-3 May 2002, San Diego, CA., pp. 172-173, 2002.

Gray, W. M.: The mutual variation of wind, shear, and baroclinicity in the cumulus convective atmosphere of the hurricane, Mon. Weather Rev., 95, 55-73, 1967.

Gray, W. M.: Global view of the origin of tropical disturbances and storms, Mon. Weather Rev., 96, 669-700, 1968.

Grell, G. A.: Prognostic evaluation of assumptions used by cumulus parameterizations, Mon. Weather Rev., 121, 764-787, 1993.

Grell, G. A., Dudhia, J., and Stauffer, D. R.: A description of the fifth-generation Penn State/NCAR Mesoscale Model (MM5), National Centre for Atmospheric Research, Boulder, Co, 122 pp., 1995.

Heymsfield, G. M., Halverson, J. B., Simpson, J., Tian, L., and Bui, T. P.: ER-2 Doppler radar investigations of the eyewall of Hurricane Bonnie during the Convection and Moisture Experiment-3, J. Appl. Meteor., 40, 1310-1330, 2001.

Huffman, G. J., Adler, R. F., Bolvin. D. T., Gu, G., Nelkin, E. J., Bowman, K. P., Hong, Y., Stocker, E. F., and Wolff, D. B.: The TRMM Multisatellite Precipitation Analysis (TMPA): QuasiGlobal, Multiyear, Combined-Sensor Precipitation Estimates at Fine Scales, J. Hydrometeor., 8, 38-55, doi:10.1175/JHM560.1, 2007.

India Meteorology Department (IMD): Report on Cyclonic disturbances over North Indian Ocean during 1999, RSMC-Tropical Cyclones, IMD, New Delhi, 2000.

Jiang, H., Halverson, J. B., and Simpson, J.: On the differences in storm rainfall from Hurricanes Isidore and Lili. Part I: Satellite observations and rain potential, Weather Forecasting, 23, 44-61, 2008.

Jones, R. W.: A three-dimensional tropical cyclone model with release of latent heat by the resolvable scales, J. Atmos. Sci., 37, 930-938, 1980.

Kain, J. S.: The Kain-Fritsch convective parameterization: an update, J. Appl. Meteor., 43, 170-181, 2004.

Kain, J. S. and Fritsch, J. M.: Convective parameterization for mesoscale models: The Kain-Fritsch scheme. The representation of cumulus convection in numerical models, Meteorol. Monogr. Amer. Met. Soc., 46, 165-170, 1993.

Kiehl, J. T., Hack, J. J., and Briegleb, B. P.: The simulated earth radiation budget of the NCAR CCM2 and comparison with the earth radiation budget experiment, J. Geophys. Res., 99, 2081520827, 1994.

Kotroni, V. and Lagouvardos, K.: Evaluation of MM5 HighResolution Real-Time Forecasts over the Urban Area of Athens, Greece, J. Appl. Meteor., 43, 1666-1678, 2004.

Kuma, K., Cho, C.-H., Muroi, C., and Ueno, M.: Improvement of typhoon track forecast by the JMA global model: An im- pact of cumulus parameterization, Papers presented at the third Technical Conference on SPECTRUM. Report No. T CP-33, WMO/TD-No. 595. World Meteor. Org., Geneva, Switzerland, IV 1-8, 1993.

Kuo, H. L.: Further studies of the parameterization of the influence of cumulus convection on large scale flow, J. Atmos. Sci., 31, 1232-1240, 1974

Kuo, Y.-H. and Anthes, R. A.: Semiprognostic tests of Kuo-type cumulus parameterization schemes in an extratropical convective system, Mon. Weather Rev., 112, 1498-1509, 1984.

Lord, S. J. and Lord, J. M.: Vertical velocity structures in an axisymmetric, nonhydrostatic tropical cyclone model, J. Atmos. Sci., 45, 1453-1461, 1988.

Lord, S. J., Willoughby, H. W., and Piotrowicz, J. M.: Role of a parameterized ice-phase microphysics in an axisymmetric tropical cyclone model, J. Atmos. Sci., 41, 2836-2848, 1984.

Mandal, M. and Mohanty, U. C.: Numerical experiments for improvement in mesoscale simulation of Orissa super cyclone, Mausam, 57, 79-96, 2006.

Mandal, M., Mohanty, U. C., and Raman, S.: A study on the impact of parametrization of the physical processes on prediction of tropical cyclones over the Bay of Bengal with NCAR/PSU mesoscale model, Natural Hazards, 31, 391-414, 2004.

Mcbride, J. L. and Zehr, R.: Observational analysis of tropical cyclone formation, Part II: Comparison of non-developing versus developing systems, J. Atmos. Sci., 38, 1132-1151, 1981.

McCumber, M., Tao, W.-K., and Simpson, J.: Comparison of icephase microphysical parameterization schemes using numerical simulation of tropical convection, J. Appl. Meteor., 30, 9851004, 1991.

Mellor, G. L. and Yamada, T.: Development of a turbulence closure model for geophysical fluid problems, Rev. Geophys. Space Phys., 20, 851-875, 1982.

Merrill, R. T.: Environmental Influence on Hurricane Intensification, J. Atmos. Sci., 45, 1678-1687, 1988.

Meyers, M. P., DeMott, P. J., and Cotton, W. R.: New primary icenucleation parameterization in an explicit cloud model, J. Appl Meteor., 31, 708-721, 1992.

Mohanty, U. C., Mandal, M., and Raman, S.: Simulation of Orissa Super Cyclone (1999) using PSU/NCAR Mesoscale Model, Natural Hazards, 31, 373-390, 2004.

Molinari, J. and Dudek, M.: Parameterization of convective precipitation in mesoscale numerical models: A critical review, Mon Weather Rev., 120, 326-344, 1992.

Moorthi, S. and Suarez, M. J.: Relaxed Arakawa-Schubert: A parameterization of moist convection for general circulation models, Mon. Weather Rev., 120, 978-1002, 1992.

Mukhopadhyay, P., Taraphdar, S., and Goswami, B. N.: Influence of moist processes on track and intensity forecast of cyclones over the north Indian Ocean, J. Geophys. Res., 116, D05116, doi:10.1029/2010JD014700, 2011.

Murata, A. and Ueno, M.: The effects of different cumulus parameterization schemes on the intensity forecast of Typhoon Flo 1990, J. Meteorol. Soc. Japan, 78, 819-833, 2000.

Neumann, C. J.: The Joint Typhoon Warning Center (JTWC92) model, SAIC, Final Report, Contract No. N00014-90-C-6042, 85 pp., 1992.

Pattnaik, S. and Krishnamurti, T. N.: Impact of cloud microphysical processes on hurricane intensity, part 1: Control run, Meteorol. 
Atmos. Phys., 97, 117-125, 2007a.

Pattnaik, S. and Krishnamurti, T. N.: Impact of cloud microphysical processes on hurricane intensity, part 2: Sensitivity experiments, Meteorol. Atmos. Phys., 97, 127-147, 2007b.

Pattnaik, S., Inglish, C., and Krishnamurti, T. N.: Influence of RainRate Initialization, Cloud Microphysics, and Cloud Torques on Hurricane Intensity, Mon. Weather Rev., 139, 627-649, 2011.

Puri, K. and Miller, M. J.: Sensitivity of ECMWF analysis-forecast of tropical cyclones to cumulus parameterization, Mon. Weather Rev., 118, 1709-1741, 1990.

Rao, D. V. B. and Prasad, D. H.: Numerical prediction of Orissa super cyclone (1999): Sensitivity to the parameterization of convection, boundary layer and explicit moisture processes, Mausam, 57, 61-78, 2006.

Rao, D. V. B. and Prasad, D. H.: Sensitivity of tropical cyclone intensification to boundary layer and convective processes, Nat Hazards, 41, 429-445, 2007.

Rao, G. V. and MacArthur, P. D.: The SSM/I estimated rainfall amounts of tropical cyclones and their potential in predicting the cyclone intensity changes, Mon. Weather Rev., 122, 1568-1574, 1994.

Reisner, J., Rasmussen, R. J., and Bruintjes, R. T.: Explicit forecasting of supercooled liquid water in winter storms using the MM5 mesoscale model, Q. J. Roy. Meteorol. Soc., 124B, 1071-1107, 1998.

Riehl, H. and Malkus, J.: Some aspects of hurricane Daisy, 1958, Tellus, 13, 181-213, 1961.

Ritchie, E. A.: Topic 1.2: Environmental effects. Topic Chairman and Rapporteur Report, The 5th WMO InternationalWorkshop on Tropical Cyclones IWTC-V,WMO Tech. Doc. WMO=TD 1136, 2002.

Rodgers, E. B. and Pierce, H. F.: Environmental influence on Typhoon Bobbie's precipitation distribution, J. Appl. Meteorol., 34, 2513-2532, 1995.

Rodgers, E. B., Baik, J. J., and Pierce, H. F.: The environmental influence on tropical cyclone precipitation, J. Appl. Meteorol., 33, 573-593, 1994a.

Rodgers, E. B., Chang, S. W., and Pierce, H. F.: A satellite observational and numerical study of precipitation characteristics in western North Atlantic tropical cyclones, J. Appl. Meteor., 33, 129-139, 1994b.

Rodgers, E. B., Olson, W. S., Karyampudi, V. M., and Pierce, H. F.: Satellite-derived latent heating distribution and environmental influences in Hurricane Opal (1995), Mon. Weather Rev., 126, 1229-1247, 1998.

Rodgers, E. B., Olson, W., Halverson, J., Simpson, J., and Pierce, H. F.: Environmental forcing of Supertyphoon Paka's (1997) latent heat structure, J. Appl. Meteor., 39, 1983-2006, 2000.

Rosenthal, S. L.: Numerical simulation of tropical cyclone development with latent heat release by resolvable scales. I: Model description and preliminary results, J. Atmos. Sci., 35, 258-271, 1978.

Schultz, P.: An explicit cloud physics parameterization for operational numerical weather prediction, Mon. Weather Rev., 123, 3331-3343, 1995.

Simpson, J., Halverson, J. B., Ferrier, B. S., Petersen, W. A., Simpson, R. H., Blakeslee, R., and Durden, S. L.: On the Role of "Hot Towers" in Tropical Cyclone Formation, Meteorol. Atmos. Phys., 67, 15-35, 1998.
Smith, R. K.: The role of cumulus convection in hurricanes and its representation in hurricane models, Rev. Geophys., 38, 465-489, 2000.

Srinivas, C. V., Venkatesan, R., Rao, D. V. B., and Prasad, D. H.: Numerical simulation of Andhra Severe Cyclone (2003): Model sensitivity to the boundary layer and convection parameterization, Pure Appl. Geophys., 164, 1465-1487, 2007.

Stensrud, D. J.: Parameterization Schemes: Keys to Understanding Numerical Weather Prediction Models, Cambridge University Press, 488 pp., 2007.

Tao, W. K. and Simpson, J.: The Goddard cumulus ensemble model. Part I: Model description, Terr. Atmos. Ocean Sci., 4, 35-72, 1993,

http://www.ocean-sci.net/4/35/1993/.

Thompson, G., Rasmussen, R. M., and Manning, K.: Explicit forecast of winter precipitation using an improved bulk microphysics scheme: Part I: description and sensitivity analysis, Mon. Weather Rev., 132, 519-542, 2004.

Trivedi, D. K., Mukhopadhyay, P., and Vaidya, S. S.: Impact of physical parameterization schemes on the numerical simulation of Orissa super cyclone, Mausam, 57, 97-110, 2006.

Trivedi, J., Sanjay, J., and Singh, S. S.: Numerical simulation of a super cyclonic storm, Orissa 1999: impact of initial conditions, Meteor. Appl., 9, 367-376, 2002.

Tsutsui, J., Kasahara, A., and Hirakuchi, H.: Impacts of diabatic initialization and cumulus parameterization on numerical typhoon prediction, J. Meteor. Soc. Japan, 76, 889-907, 1998.

Tuleya, R. E.: Tropical storm development and decay: Sensitivity to surface boundary conditions, Mon. Weather Rev., 122, 291-304, 1994.

Tuleya, R. E. and Kurihara, Y.: A numerical study on the effects of environmental flow on tropical storm genesis, Mon. Weather Rev., 109, 2487-2506, 1981.

Uppala, S. M., Kallberg, P. W., Simmons, A. J., Andrae, U., Bechtold, V. D., Fiorino, M., Gibson, J. K., Haseler, J., Hernandez, A., Kelly, G. A., Li, X., Onogi, K., Saarinen, S., Sokka, N., Allan, R. P., Andersson, E., Arpe, K., Balmaseda, M. A., Beljaars, A. C. M., Van De Berg, L., Bidlot, J., Bormann, N., Caires, S., Chevallier, F., Dethof, A., Dragosavac, M., Fisher, M., Fuentes, M., Hagemann, S., Holm, E., Hoskins, B. J., Isaksen, L., Janssen, P. A. E. M., Jenne, R., McNally, A. P., Mahfouf, J. F., Morcrette, J. J., Rayner, N. A., Saunders, R. W., Simon, P., Sterl, A., Trenberth, K. E., Untch, A., Vasiljevic, D., Viterbo, P., and Woollen, J.: The ERA-40 re-analysis, Q. J. Roy. Meteorol. Soc., 131, 2961-3012, 2005.

Wang, Y.: An explicit simulation of tropical cyclones with a triply nested movable mesh primitive equation model: TCM3. Part II: Model refinements and sensitivity to cloud microphysics parameterization, Mon. Weather Rev., 130, 3022-3036, 2002.

Wang, Y.: How do outer spiral rainbands affect tropical cyclone structure and intensity?, J. Atmos. Sci., 66, 1250-1273, 2009.

Wang, Y. and Wu, C.-C.: Current understanding of tropical cyclone structure and intensity changes - A review, Meteor. Atmos. Phys., 87, 257-278, 2004.

Weisman, M. L., Klemp, J. B., and Skamarock, W. C.: The resolution dependence of explicitly modeled convective systems, Mon. Weather Rev., 125, 527-548, 1997.

Willoughby, H. E., Jin, H. L., Lord, S. J., and Piotrowicz, J. M.: Hurricane structure and evolution as simulated by an axisymmet- 
ric nonhydrostatic numerical model, J. Atmos. Sci., 41, 15681589, 1984.

Wu, C.-C. and Cheng, H.-J.: An observational study of environmental influences on the intensity changes of Typhoons Flo (1990) and Gene (1990), Mon. Weather Rev., 127, 3003-3031, 1999.

Wu, L. and Wang, B.: Effects of convective heating on movement and vertical coupling of tropical cyclones: A numerical study, J. Atmos. Sci., 58, 3639-3649, 2001.

Yamasaki, M.: A preliminary experiment of the tropical cyclone without parameterizing the effect of cumulus convection, J. Meteor. Soc. Japan, 55, 11-30, 1977.

Zehr, R. M.: Tropical cyclogenesis in the western North Pacific, NOAA Tech. Rep. NESDIS 61, 181 pp., 1992.
Zeng, Z., Wang, Y., and Wu, C. C.: Environmental dynamical control of tropical cyclone intensity - An observational study, Mon. Weather Rev., 135, 38-59, 2007.

Zhang, D.-L., Hsie, E.-Y., and Moncrieff, M. W.: A comparison of explicit and implicit predictions of convective and stratiform precipitating weather systems with a meso-_-scale numerical model, Q. J. Roy. Meteorol. Soc., 114, 31-60, 1988.

Zhu, T. and Zhang, Da-Lin: Numerical simulation of hurricane Bonnie (1998). Part II: Sensitivity to varying cloud microph4ysical processes, J. Atmos. Sci., 63, 109-126, 2006. 